\title{
Cooperation between orthodontic and surgical practitioners when dealing with facial asymmetry Orthodontic and surgical cooperation in facial asymmetry
}

\author{
O. Esnault' ${ }^{1}$ T. Dang ${ }^{2}$, A. Marinetti², G. Joseph ${ }^{2}$ \\ 1 Maxillofacial Surgeon \\ 2 Specialist certified in dentofacial orthopedics
}

\begin{abstract}
Facial asymmetry is frequent and remains an orthodontic and surgical challenge. Successful treatment depends on accurate diagnosis and close cooperation between the orthodontist and the surgeon, the aim being to restore functional balance. Recovering facial symmetry also favours the patient's social and professional integration. After recalling the different elements of the diagnosis, specific orthodontic care is detailed for each type of asymmetry and adapted surgical means are described. Clinical cases illustrate each situation and provide the practitioner with precise indications on the treatment.
\end{abstract}

\section{KEYWORDS}

Asymmetry, orthodontics, surgery, indications, cooperation

\section{INTRODUCTION}

The treatment of asymmetries of the face, more commonly referred to as facial asymmetries, does not require only medical knowledge and a careful examination, but more importantly, it require multiple, fruitful exchanges between an orthodontist and a surgeon. Our goal is not to rehash the exhaustive list of all conditions that can be responsible for facial asymmetry but rather to pragmatically organize the combined treatment of patients with this condition by two medical specialists who need to be perfectly synchronized to provide their patient the best possible treatment.

Therefore, we will not specifically discuss the conditions that can cause facial asymmetries such as craniosynostosis or facial grooves as the focus here is on orthodontic-surgical techniques that are more widely applicable. 
Finally, this overview is essentially incomplete and can only supplement the collective experiences of orthodontic and surgical practitioners with- in recent years. We intend to build a canvas where each person can come and add their mark to this piece.

\section{THE INTIAL ASSESSMENT}

\section{Anamnesis}

First, we will investigate any personal or familial history of facial asymmetry: an injury, however small, on the chin or even joint inflammation. We will also attempt to quantify how the asymmetry has progressed and will eventually achieve this by referring to patient photographs. This information will be made available when we retrieve the photographic and radiological files previously created for the patient by fellow practitioners.

These elements are important because they are going to change the attitude to treatment and provide justification to the patient and their family. It is also crucial to consider the patient's request as they can be more concerned with the esthetics and symmetry as opposed to occlusion and impaired functions.

\section{Clinical Examination ${ }^{18}$}

\section{Extraoral: examination and photograph analysis}

The clinical examination of the face is just as important as the patient's photographs that must be carefully taken, ideally with the patient being able to note any associated postural asymmetries.

\section{- Frontal}

From the front, face snapshots should be centered from the vertex to the shoulders, asking the patient to look straight ahead with eyes wide open. The bi-pupillary line must be horizontal if possible.

Each ear lobe must be visible to evaluate the asymmetric layout.

The way the patient smiles is essential. The photo, according to normal orthodontic standards (threequarter, head turned toward the target) is not very useful here. It is advisable to use a Fox plane plate with a graduated gauge attached to the patient, which will allow for precise measurements to be taken in the event of an oblique occlusal plane in the frontal plane.

A standing shot with both lips parted is also very useful.

We will assess the height differential between the left/right facial sections (anterior vertical dimension) and the bi-pupillary and bi-commissural lines (fig. 1a).

\section{- Profile}

One photo of each profile is indispensable, which is ideally taken by asking the patient to look directly into their eyes reflected in a mirror mounted on a wall. 

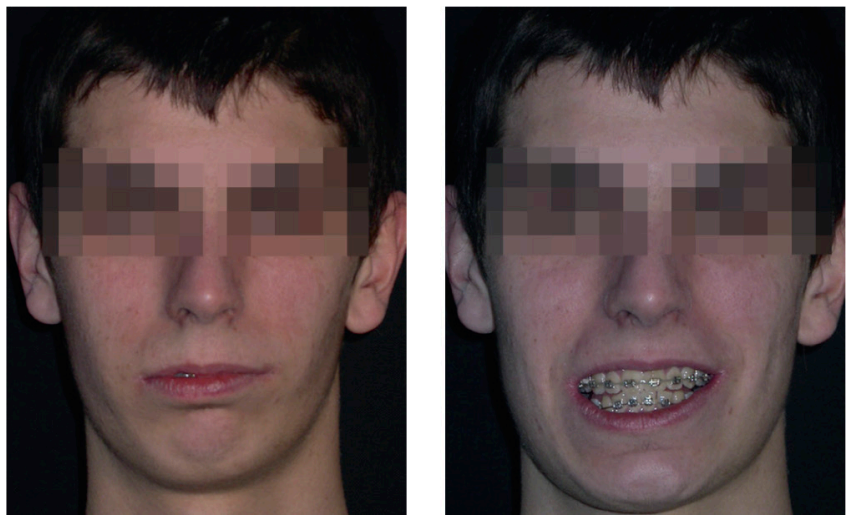

Figure 1

a) The bi-commissural line is not parallel to the bi-pupillary line, which indicates that the patient has an occlusal cant and a midline deviation.

\section{- Additional shots}

A three-quarter right-to-left shot and a shot from the bottom-up view (Hirtz position gives a good evaluation of the mandibular corpus and the angles) create a complete picture.

Each facial element will be assessed, preferably in the presence of the patient so that the patient can better understand and cooperate in the treatment plan.

- forehead: height asymmetry, hair differential, tonus differential

- eyebrows and eyes: height asymmetry, which can indicate asymmetric orbital height;

- it is important to draw the patient's attention to this asymmetry as it will require specialized treatment.

- nose deviation in relation to the midsagittal plane, asymmetrical layout of the ala nasi, deviated tip.

- chin and corpus and right and left mandibular angles; shoulders forward

Choosing a reference plane that will serve as the symmetric axis

It will be used to confirm dental midline deviation from the midsagittal plane.

This choice can be made difficult in cases of deviation of the nose or orbital asymmetry.

\section{Functional Examination}

- Palpation and auscultation of the temporomandibular joint (TMJ) (comparative) Cracking during auscultation, clattering, and pain; all anomalies must be brought to the attention of the patient to ensure that they are not side effects of the orthodontic-surgical process.

- Observation of the mandibular dimensions and of the size of buccal opening/closing. This permits a differential diagnosis between lateral deviation (kinetic) and lateral mandibular (true asymmetry). The two can be observed in the same patient. The true cause of asymmetry can be determined by comparing the maximum intercuspation and centric relation.

- Examining the facial musculature: inspection while swallowing, speaking, testing each muscular group through mimicry, and palpation during the experience of voluntary contraction. Tonus and contraction asymmetry will often have consequences for facial growth (congenital stiff necks, hemifacial spasm). 
- This functional examination will ideally be completed by a kinesiotherapist or specialist orthodontist who will be particularly interested in lingual function and in asymmetries regarding muscle function (facial, mastication, and cervical muscles). Some asymmetries can be exposed or increased by wearing disocclusion/relaxation guards, which will assist in making the diagnosis.

\section{Intraoral}

The cant of the occlusal plane into the frontal plane must first be visualized either using a tongue depressor or more specifically using a Fox plane plate. Snapshots can be taken when the patient rests the plane on the superior arch and then the inferior arch to better view the cant. (fig. $1 \mathrm{~b}$ and $\mathrm{c}$ ).

The asymmetry of the superior and inferior incisal midlines is not enough to make a diagnosis; the position of each in relation to the midsagittal plane must be determined. Dental movements and rotational forces, which compensate for basal asym- metry, must be meticulously documented.

Inspection of the palatal arch: length, shape, symmetry of maxillaries $D$ and $\mathrm{G}$ in relation to the median raphe (fig. 2).

Transverse maxillary and alveolar hypoplasia are often associated with facial asymmetry. It is advantageous to conduct a dental examination for identifying any infected sites, which can have both medicolegal repercussions.

\section{Base of the skull}

It is better to assess it using a three-dimensional (3D) X-ray examination, but a clinical examination of the asymmetry of the glenoid cavities would be useful in cases of differential layout of the auricular flaps.

\section{Additional Examinations}

\section{Plaster molds}

Mounting the molds on a joint can be a useful addition; some joints permit movement in three directions and surgical simulations.
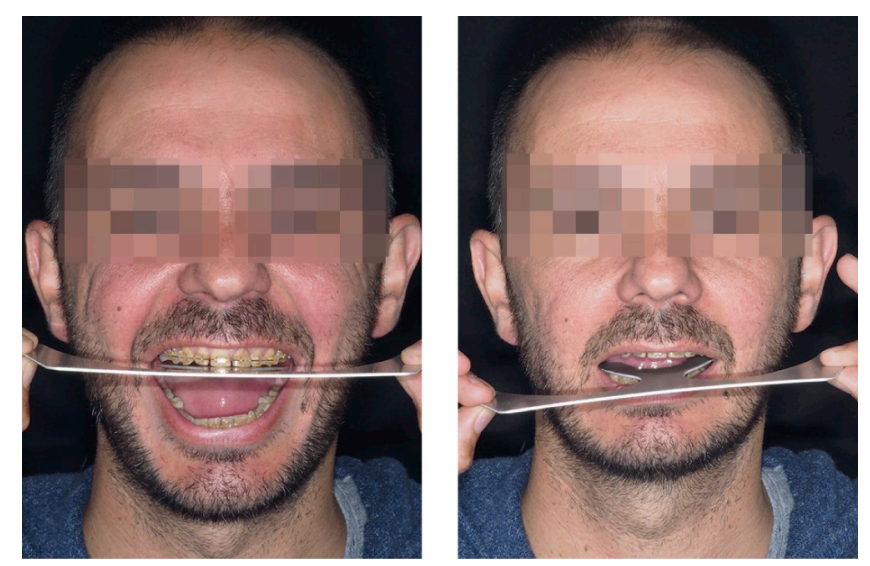

Figure 1

b) The positioning of the Fox plane plate on the superior arch shows the maxillary plane parallel to the bi-pupillary line with an interincisal midline shift to the left. The flat position-

ing of the plate on the inferior arch shows a significant cant of the mandibular plane. 

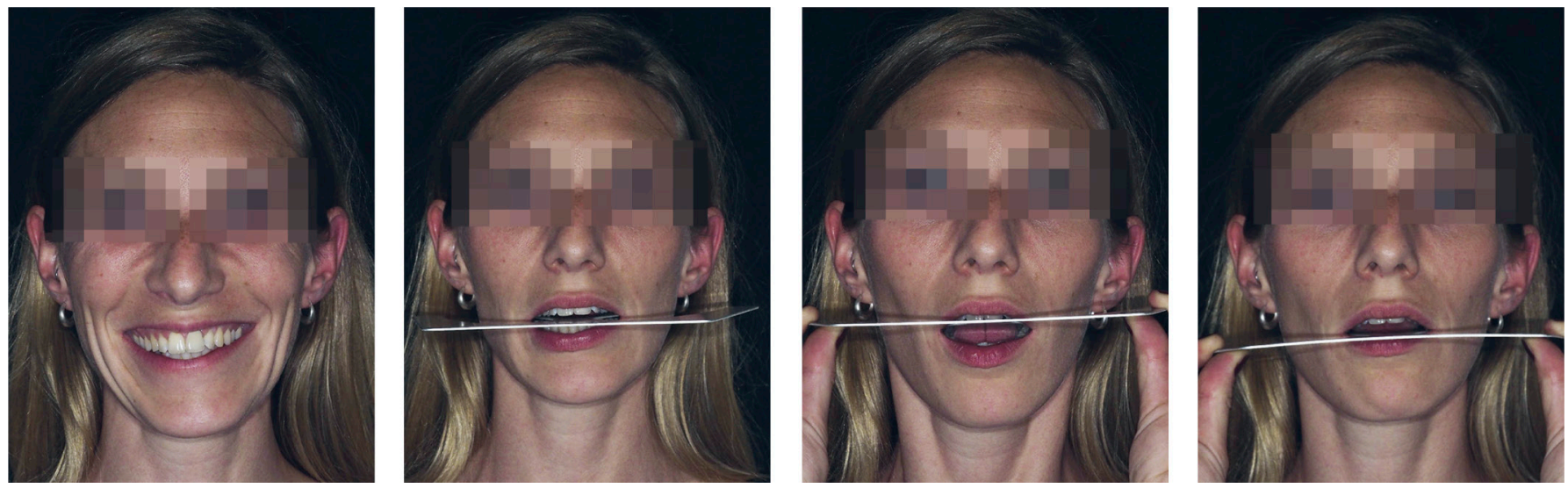

Figure 1

c) The occlusal plane is oblique in the same direction as the maxillary and mandibular planes.

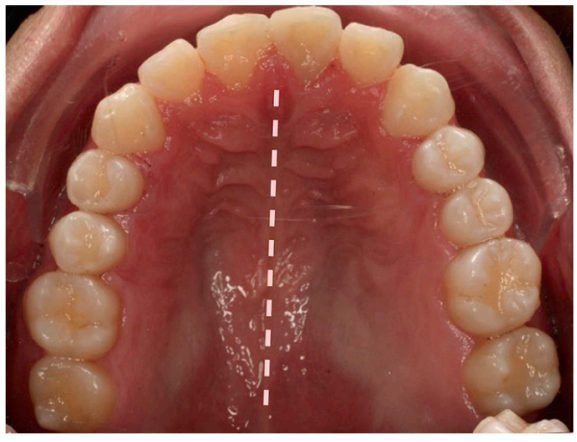

Figure 2

Occlusal shot showing maxillary asymmetries/median raphe.

\section{D Imaging: Facial cone beam}

Facial cone beam must first be prescribed. 2D and panoramic facial and profile reconstructions are performed using software and should not be overused. This imaging permits 3D rendering using photographs (fig. 3).

\section{D Analysis ${ }^{2,14}$}

The Treil28-30 method of analysis, which has the advantage of associating statistical frames with analysis architecture, is currently dominates 3D analysis.
At present, it is not used daily, but in the future, it will be able to perfectly quantify facial asymmetries and specifically determine anatomic skeletal and dental elements to be corrected.

It is a great help for making certain differential diagnoses, for example, to determine if the rotation of the maxillary or mandibular arch in relation to the cervicocaudal axis is skeletal or alveolar (fig. 4).

Some authors have recently proposed using information to identify a primary personalized midsagittal plane that will serve as a reference for the surgery ${ }^{10}$.

\section{Bone scans}

Useful for observing condylar length and shape asymmetries, it can differentiate true condylar hyperplasia from growth asymmetry or condylar hypoplasia.

When the result is positive, it provides a good basis for condylar surgery when paired with objective documentation that is easily understood by the patient. 

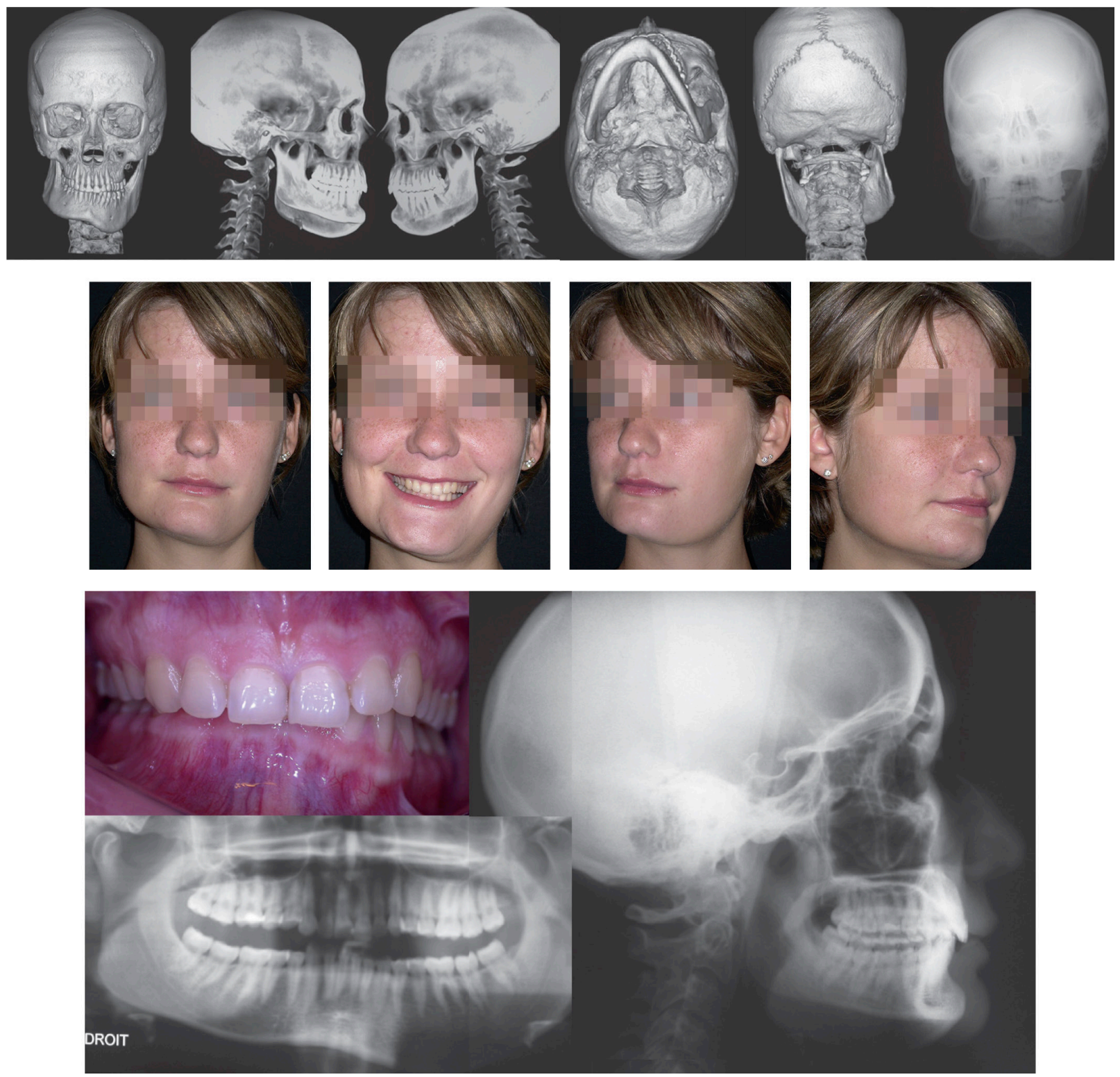

Figure 3

3D examination that refines completed photo examinations. The 3D examination can be compared to the snapshots taken.

\section{DIAGNOSIS}

Following the assessment, the asymmetry can now be specifically identified ${ }^{1,9,18,21,26,27}$. The anamnesis and retrieved documents can provide evidence of a lateral mandibular deviation that was untreated in childhood. In the context of prognathia, for example, it could be because of ankylosis or temporomandibular post-traumatic growth asymmetry or even be a hereditary condition.

The analysis of some patients shows that asymmetries frequently affect the lower-third (more than 2/3 cases) and, 


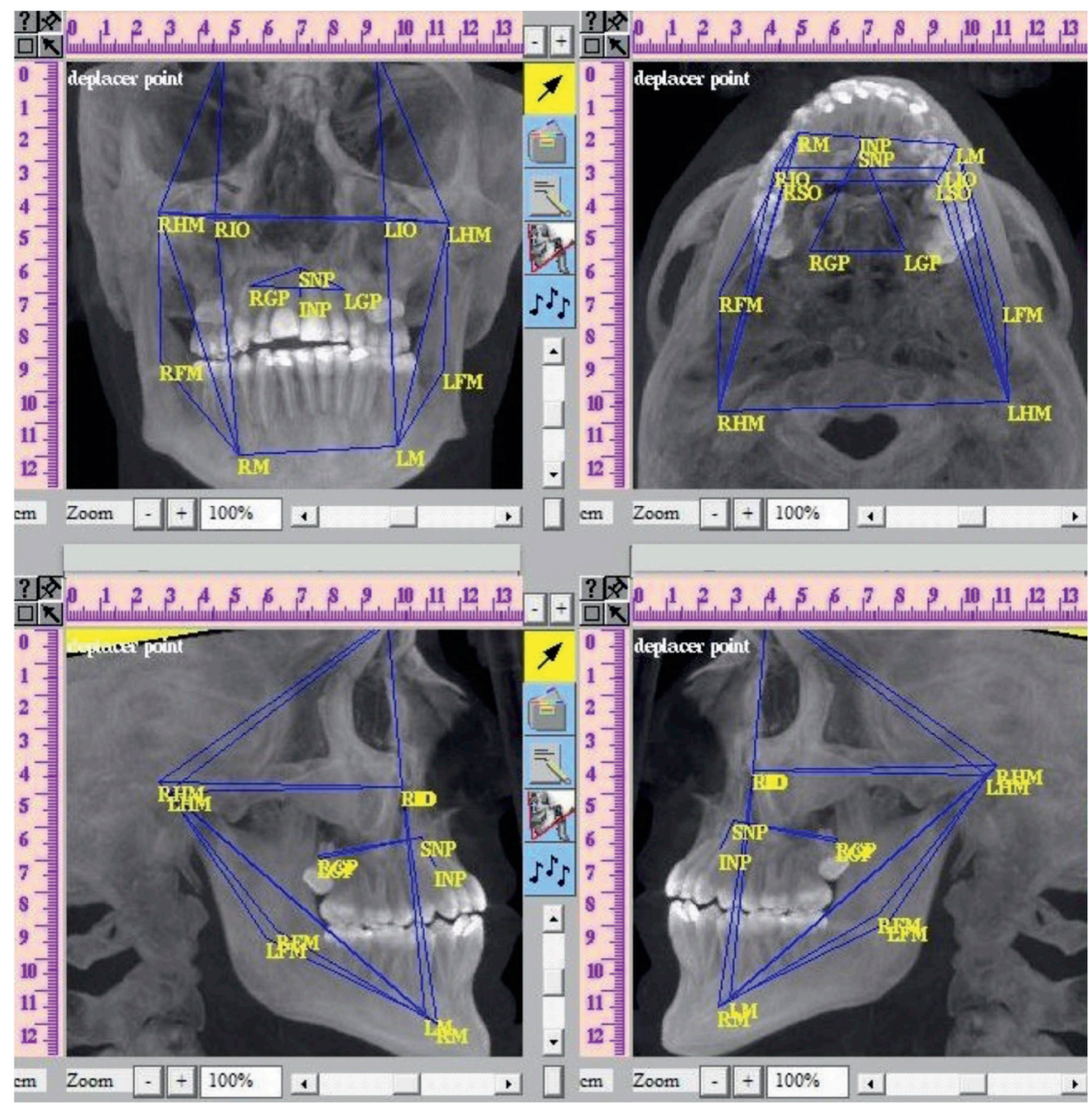

Figure 4

3D analysis with Treil.

in a lower proportion, the middle-third (1/3 cases) of the face with occlusal plane cants in the same proportion ${ }^{24,3}$.

\section{Alveolar Diagnosis ${ }^{25}$}

Alveolar rotation of the arch is often found in asymmetric dental extractions or the unilateral agenesis. A difference in the alveolar height, maxillary and or mandibular, can be seen. These anomalies are frequently seen in Brodie's syndrome.

A dental arch in a helical shape can be difficult to fix if compensations are antagonistic between the superior and inferior arches.

Torque anomalies of the tip may be kept if they are favorable to basal bone displacements in surgery; otherwise, they will be corrected if alveolar compensations impair the surgeon.

\section{Basal Diagnosis}

- Rotation around the maxillary or mandibular cephalocaudal axis (facial scoliosis).

- Cant of the occlusal plane in the frontal plane.

- Height difference between the two mounting mandibular branches.

- Lateral mandibular: mandibular dysmorphia in the transverse dimension.

- Laterogenia: lateral deviation of the chin. 


\section{EACH PERSON'S ROLE (DECISION TREE, FIG. 19)}

An orthodontist, like a surgeon, will have a major input for correcting asymmetries of the lower and middle sections of the face. Ideally, a patient must be independently examined by each professional and then the file and relevant documents can be jointly reviewed so that the treatment plan can be explained to the patient by the two major specialists. This procedure allows the examination to be conducted without any initial influence and allows each specialist to learn from the other and to have a common discourse and vision that greatly reassures the patient ${ }^{23}$.

\section{THE ORTHODONTIST'S ROLE}

It consists of conducting a precise examination of dentoalveolar positions in the basal bone to decompensate natural alveolar compensations and unlock the arches independently. The simple question to the complex response could be "where should the teeth be at the end of treatment?"

In cases of purely basal asymmetry, the orthodontist strives to re-center the teeth in the three planes of space on an asymmetrical bone base. Thus, basal correction is possible without surgical intervention. This alveolar decompensation is sometimes complex and can require bone anchorages (that limit the effects of parasites), wedges, guards, or lifting planes.

When the anomaly is completely alveolar on a symmetrical bone base, the orthodontist can sometimes symmetrize the arches, thereby leaving only sagittal corrections for the surgeon to correct.

\section{Correcting intra-arch asymmetries}

In case of extraction or agenesis in only one area, contralateral extraction can be chosen to symmetrize the arch and re-center the interincisal midline so that the surgeon would only have to make a sagittal correction. In other situations, when the number of extractions or ageneses is too significant, it would be preferable to reopen the space to symmetrize the arch.

The role of the orthodontist is now to create sufficient space between dental apices to allow the surgeon to create a vertical osteotomy line for distracting the bone and recreating the space (fig. 5).

\section{Correction of occlusal plane obliquity in the frontal plane}

In some cases, the cant of the occlusal plane is small enough to couple maxillary-alveolar correction with surgical mandibular correction.

This way, a cant of the maxillary occlusal plane of less than 2 or 3 $\mathrm{mm}$ can sometimes be corrected by an orthodontic differential egression with the surgeon only performing surgery on the mandible. This 

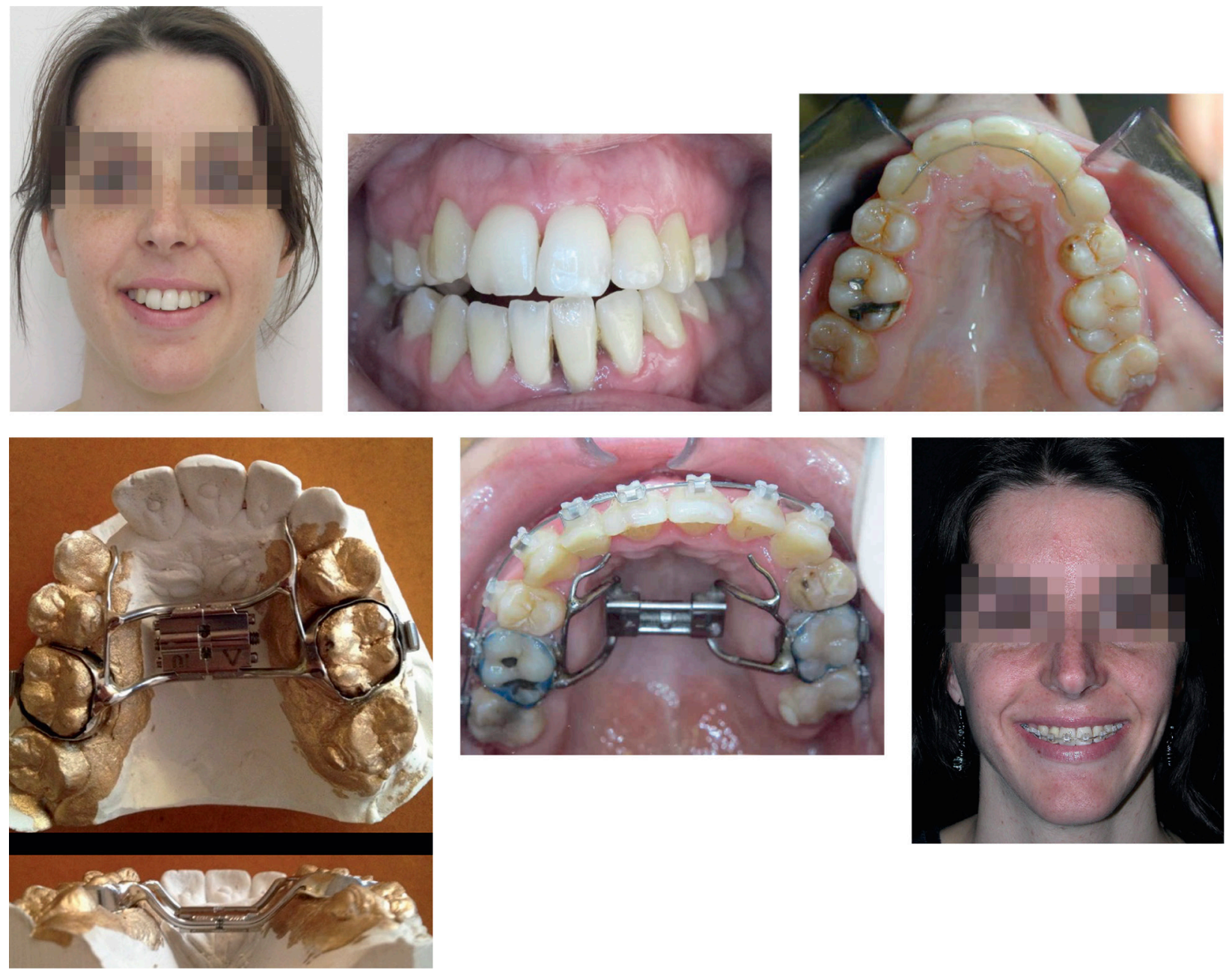

Figure 5

Extractions of the first 4 premolars with closing spaces and deviation from the maxillary interincisal midline. Asymmetrical bi-partite maxillary transversal distraction in 11/13 to create space for 12 and re-center the smile.

solution forces the orthodontist to create a unilateral wedge framing 1 or 2, which will be used in surgery to position the mandible. Once the osteotomy is made, the orthodontist can progressively remove the wedge and open up the affected maxillary zone. Placing mandibular bone anchorages next to the wedge permits controlled egression of the maxillary teeth (fig. 6).

The midlines can be centered via significant obliquity of the occlusal plane without alveolar compensation. The orthodontist's preparation is very limited (the molds now show a very good impression).

The orthodontist will therefore maintain the axes, and the surgeon will correct the basal bone (fig. 7).

If the anomaly is bi-pupillary with canting of the maxillary and mandibular planes, the orthodontic preparation of the maxilla will tend to widen the cant of the occlusal plane by decompensating the premolo-molar 

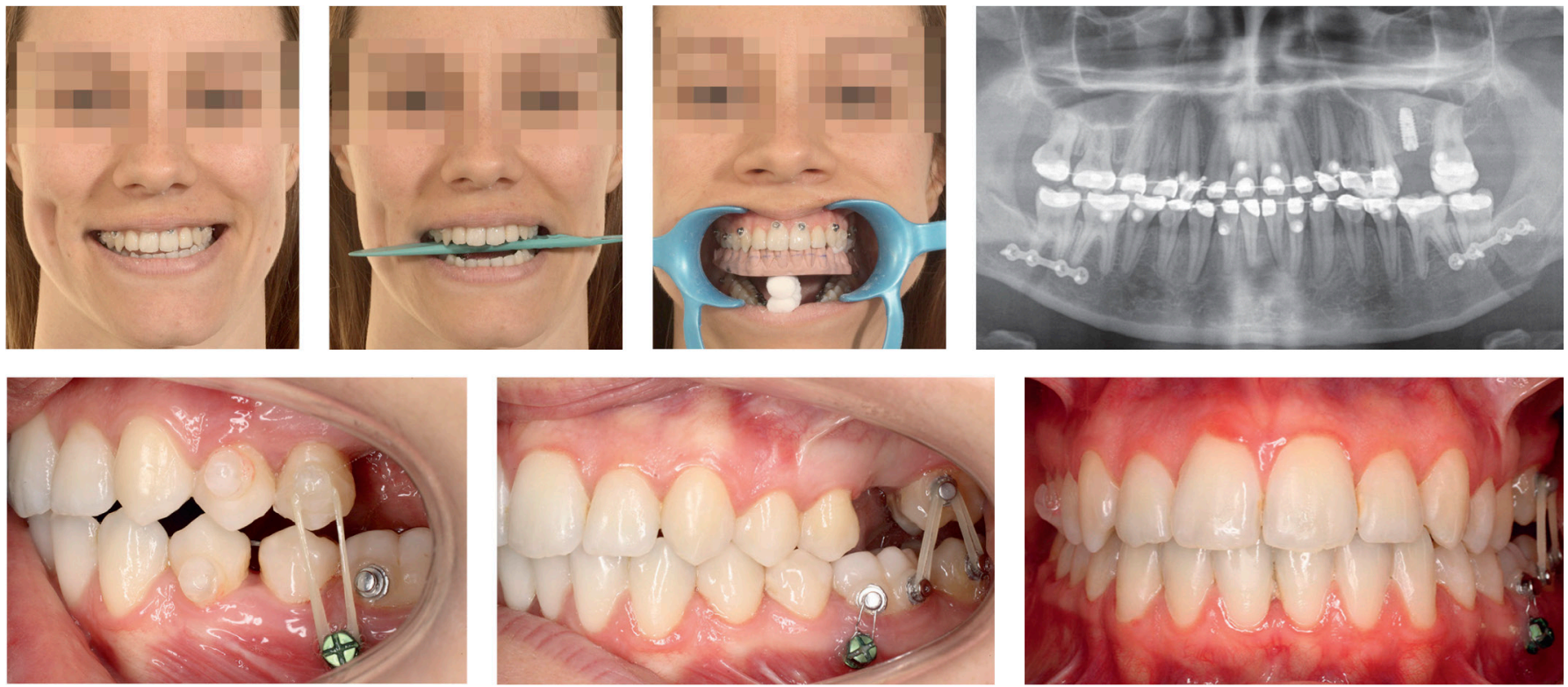

Figure 6

Obliquity of the occlusal plane and creation of a wedge on 24/25/27, which will be progressively removed up to 2 months after surgery, and then on 27 and the temporary crown 26.
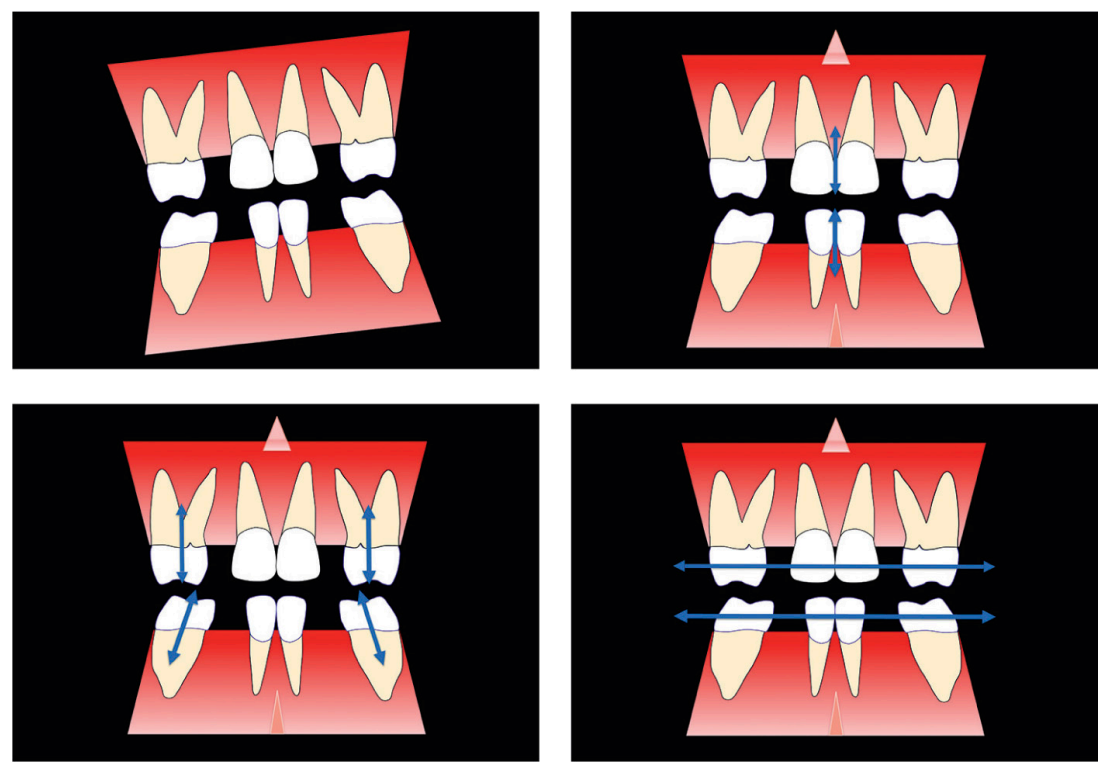

Figure 7

Maxillary and mandibular midlines are centered on the oblique basal architecture; there is little to no alveolar compensation. Surgical basal correction could be done after minimal orthodontic preparation.

zones in the direction of mandibular deviation. Theoretically, it will be necessary to achieve exo-alveolitis rela- tive to the side of the deviation and endo-alveolitis on the opposite side (fig. 8). 

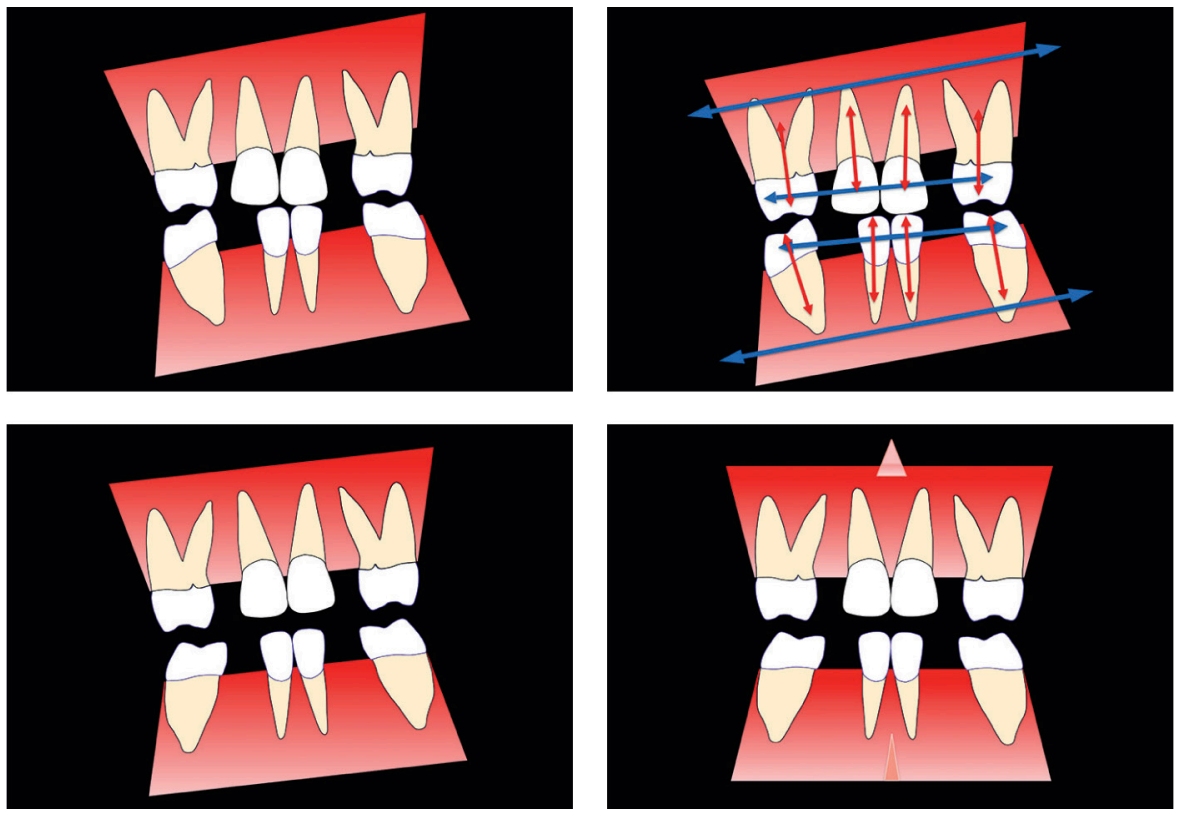

Figure 8

Diagram for orthodontic preparation in case of alveolar compensation with tip and twisting forces that are unfavorable to basal movement. Alveolar decompensation facilitates basal movement.
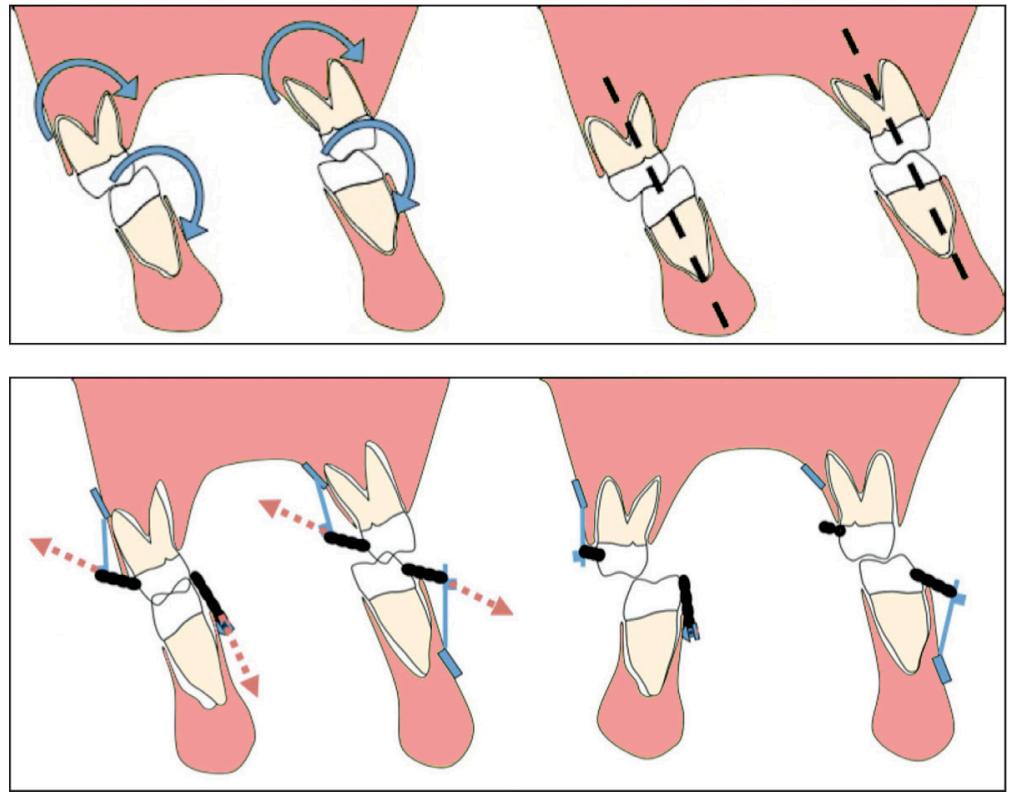

Figure 9

Using bone anchorages to facilitate alveolar decompensation (based on the work of Dr. Benoit Thébault).

The difficulty involved in the orthodontic preparation is increased by mastication, which opposes the movements of decompensation. It can be aided through the use of bone anchorage plates (fig. 9). 


\section{Lateral mandibular corrections without obliquity of the maxillary plane in the frontal plane}

One can observe purely mandibular deviations with a shorter mounting branch on one side with dento-alveolar compensation without canting of the occlusal plane. The superior interincisal midline is then centered in relation to the midsagittal plane. The inferior interincisal midline is centered on the deviated chin. The intraoral examination and molds can provide evidence of some compensations that need to be corrected by creating reverse articulation on the side of the lateral mandibular deviation and exclusion of the other side (fig. 10, 11, 12).
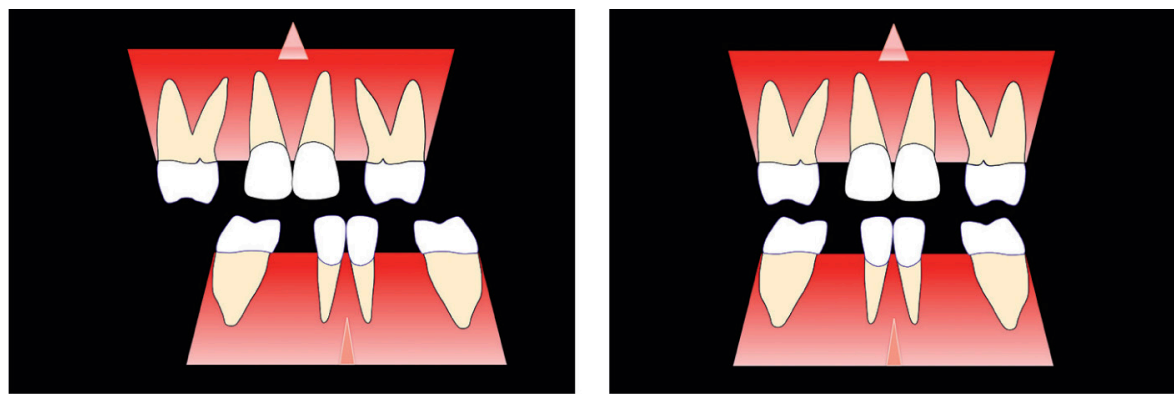

Figure 10

Diagram showing basal re-centering of the lateral mandible without frontal cant of the occlusal plane. The midlines are centered on the deviated bone. Surgical movement will simultaneously re-center the alveolar bone. Orthodontic preparation is therefore not as complex.
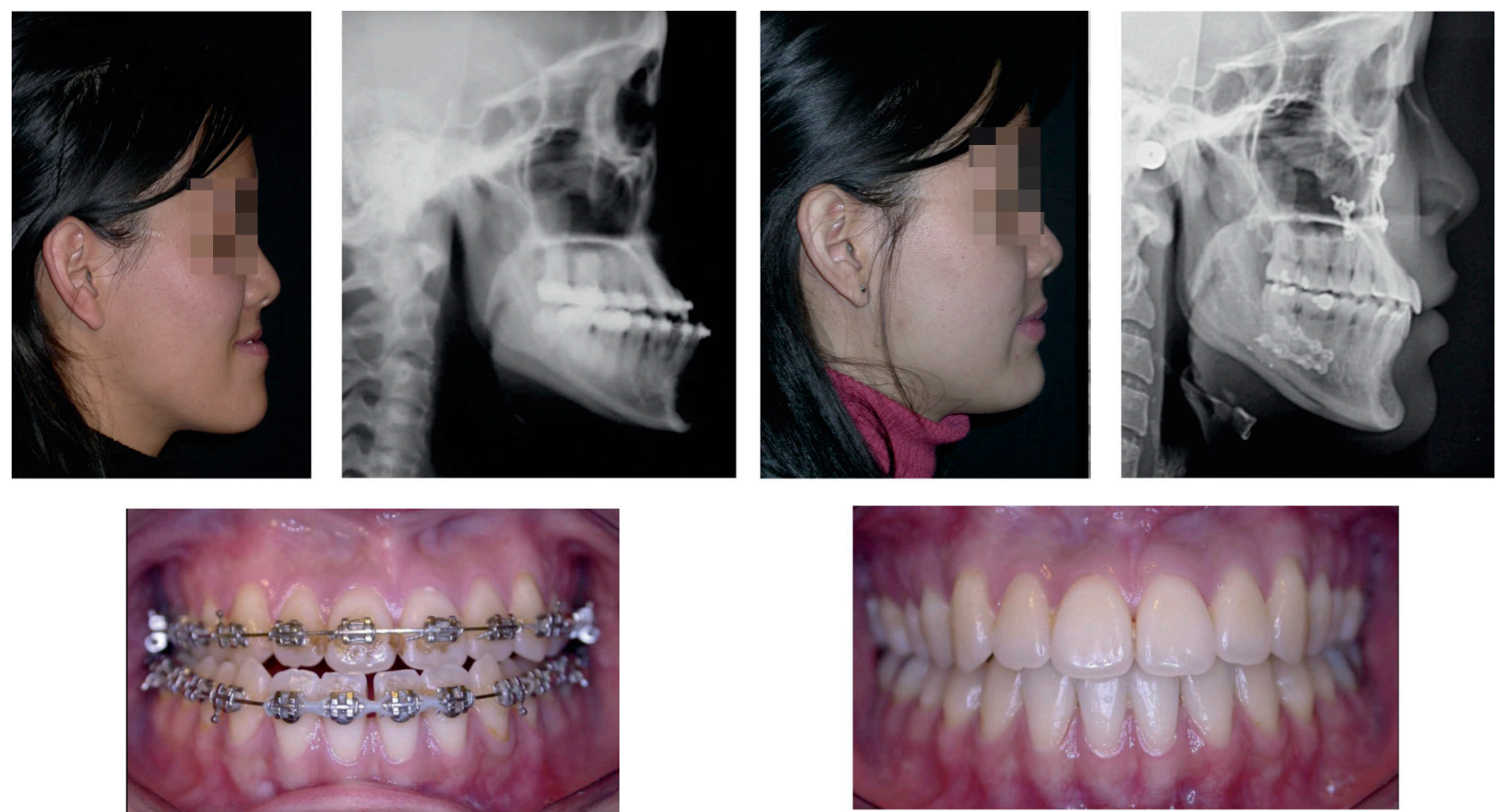

Figure 11

Class III mandibular lateral deviation and minimal transverse maxillary hypoplasia; surgical correction: advanced Le Fort 1 osteotomy with bipartite disjunction and mandibular de-rotation. 

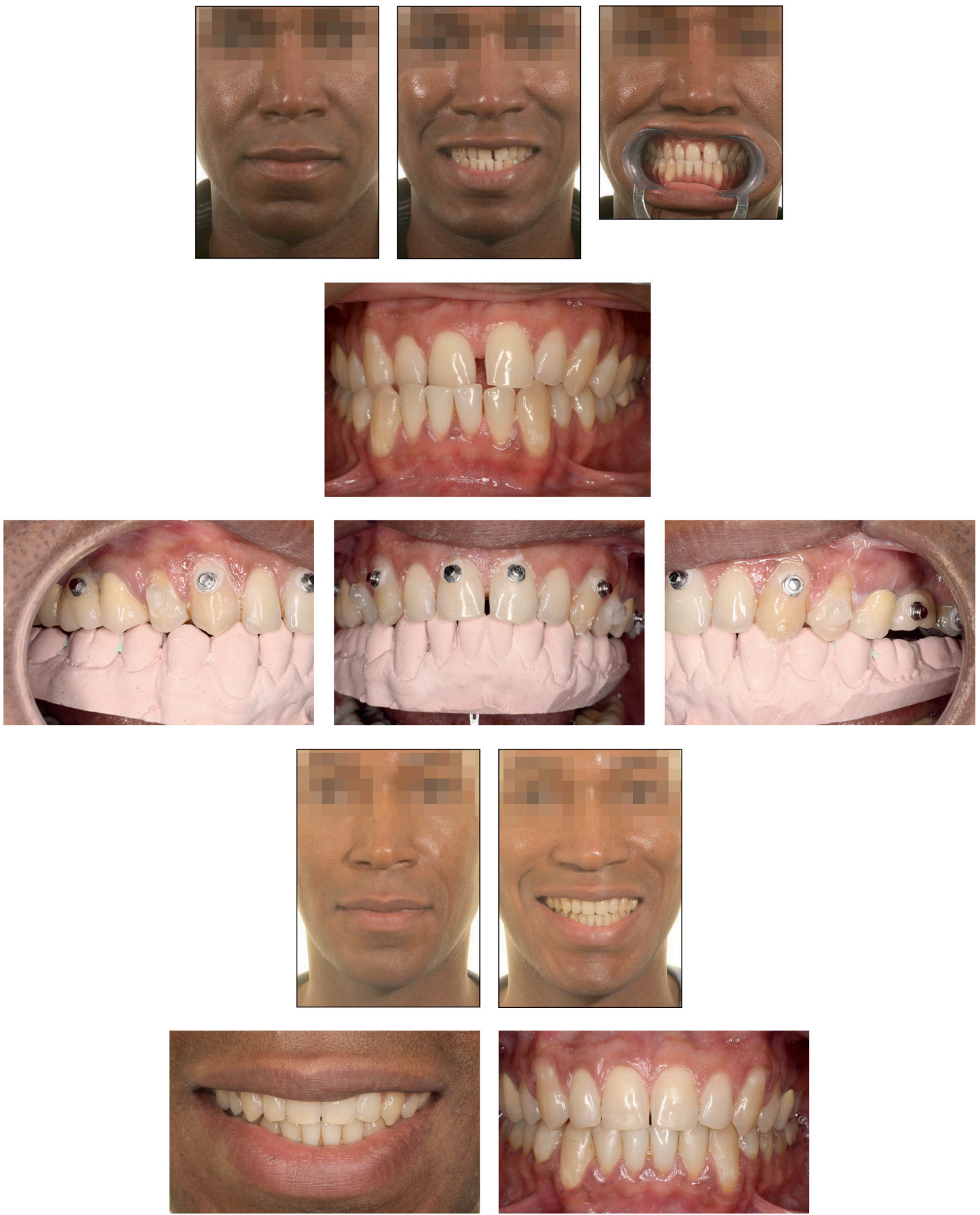

Figure 12

Example of orthodontic lingual preparation with alignment and coordination of controlled arches in the preoperative stage by positioning the mold in the mouth. 

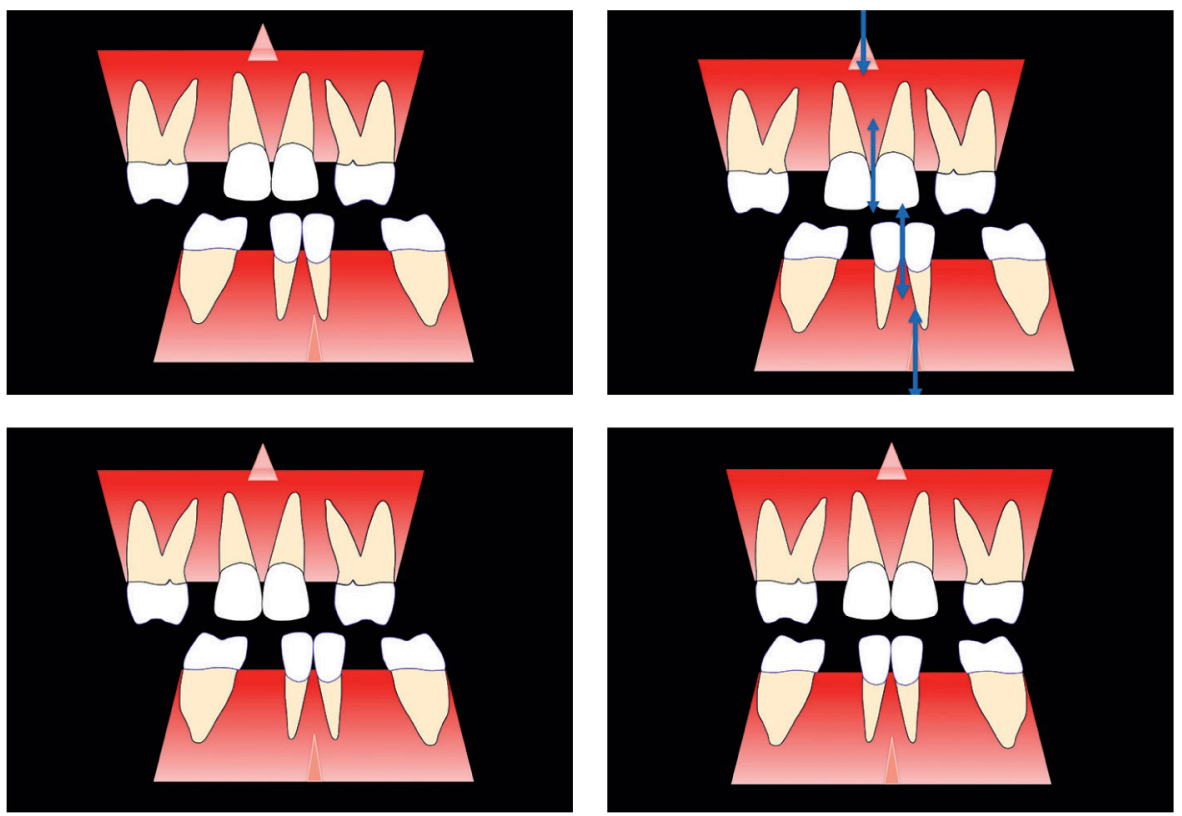

Figure 13

Diagram showing orthodontic preparation in case of alveolar compensation with spontaneous midline re-centering on a deviated bone base. Orthodontic decompensation will align the midlines on the deviated basal bone, and surgical movement will then re-center everything.

Surgical basal movement will only re-center the mandible and consequently the inferior interincisal midline. If the incisal midlines are deviated from the basal bone because of spontaneous compensation or previous orthodontic treatment, the ideal method is to center them on the basal maxillary spine and chin. This will facilitate basal surgery and improve the final result.

\section{Correcting complex asymmetries}

Facial asymmetry is too complex and is almost impossible to correct completely; therefore, a patient must agree to accept an orthodontic-surgical treatment plan that improves, but does not completely correct, it. For example, if the orbits are not horizontally aligned, then, the correction of the occlusal plane in relation to the bi-pupillary line could result in undesirable side effects. These complex cases should be monitored to amplify or expose any soft tissue asymmetry due to a single skeletal correction.

Principles of orthodontic preparation: maxillary and mandibular rotations (cephalocaudal axis)

\section{Role of the surgeon}

The surgeon must be aware of the skills of the orthodontist and their limitations in terms of putting together the best treatment plan. In some cases, earlier surgery will be indicated so that the orthodontist could easily make his corrections without occlusal interference. The creation of wedges is useful for obtaining pre-op stability. Alveolar decompensations can 
be very difficult for the orthodontist to achieve. In this regard, the surgeon can assist with corticotomies and/or the placement of bone anchorages. Some gifted surgeons can correct the majority of asymmetries (peculiar cases of condylectomies) to facilitate the work of the orthodontist.

\section{Maxillary Osteotomies Osteotomy LeFort 1}

We will not go into detail about the surgical osteotomy technique LeFort 1 here. This intervention mobilizes the superior maxillas in the three planes of space and corrects the transverse dimension, sometimes simultaneously.

All movements have been planned in close collaboration with the orthodontist to determine active dental axes.

3D simulations can help the surgeon and have developed very quickly. However, for now, they remain costly and time consuming in their implementation.

\section{Mandibular Osteotomies}

\section{Treatment of condylar hyperplasia: Condylectomy (fig. 17)}

Bone scanning can assist treatment depending on its result. In cases of moderate-to-severe advanced fixation, early condylectomy can be performed to stop asymmetric growth before making any major modifications to the occlusal plane and alveolar compensations. In the immediate postoperative period, rerouting to the other side of condylectomy is noted. This is caused by interarticular hematomas and edemas and generally ceases after a few weeks. The patient will then be monitored, and orthodontic treatment will be performed to stabilize the result into adulthood. At this stage, the patient and his/her family must be informed of the very frequent need for undergoing mono or bi-maxillary surgery in adolescence to obtain a stable and functional result.

Fortunately, the results of condylectomies are often very positive and can satisfy the patient even if they are not always stable in the long term and are perfectly functional. The major risk of this intervention is due to the frontal branch of the facial nerve, which is not generally affected but upon which the spacer or retractor comes to rest in the preoperative period. Preoperative frontal paresis is therefore possible, and it generally regresses within a few weeks. A debate persists as to the necessity of this surgery when the bone scan result is negative and there is true asymmetry of the length of the condyles without any clinical complaint about the temporomandibular joints. Some would advise repositioning condylectomy as it ensures that the incidence of side effects is quite rare and that the cost-benefit relationship seems favorable. Others feel that a joint that causes no discomfort must not, under any circumstances, be operated on and as such, they advocate for extra condylar re-centering.

\section{Caudal chrondotomy ${ }^{16}$}

This is recommended for children presenting a lack of ramus development or after the temporomandibular joint has been damaged. This 
procedure will be performed via the preauricular tissue; the site of caudal chrondotomy is extracted during the same operation. The graft is then made and placed using a "diabolo."
The patient must be monitored to ensure that a cartilage height of no more than $3 \mathrm{~mm}$ is obtained to avoid hypergrowth of the mounting branch.
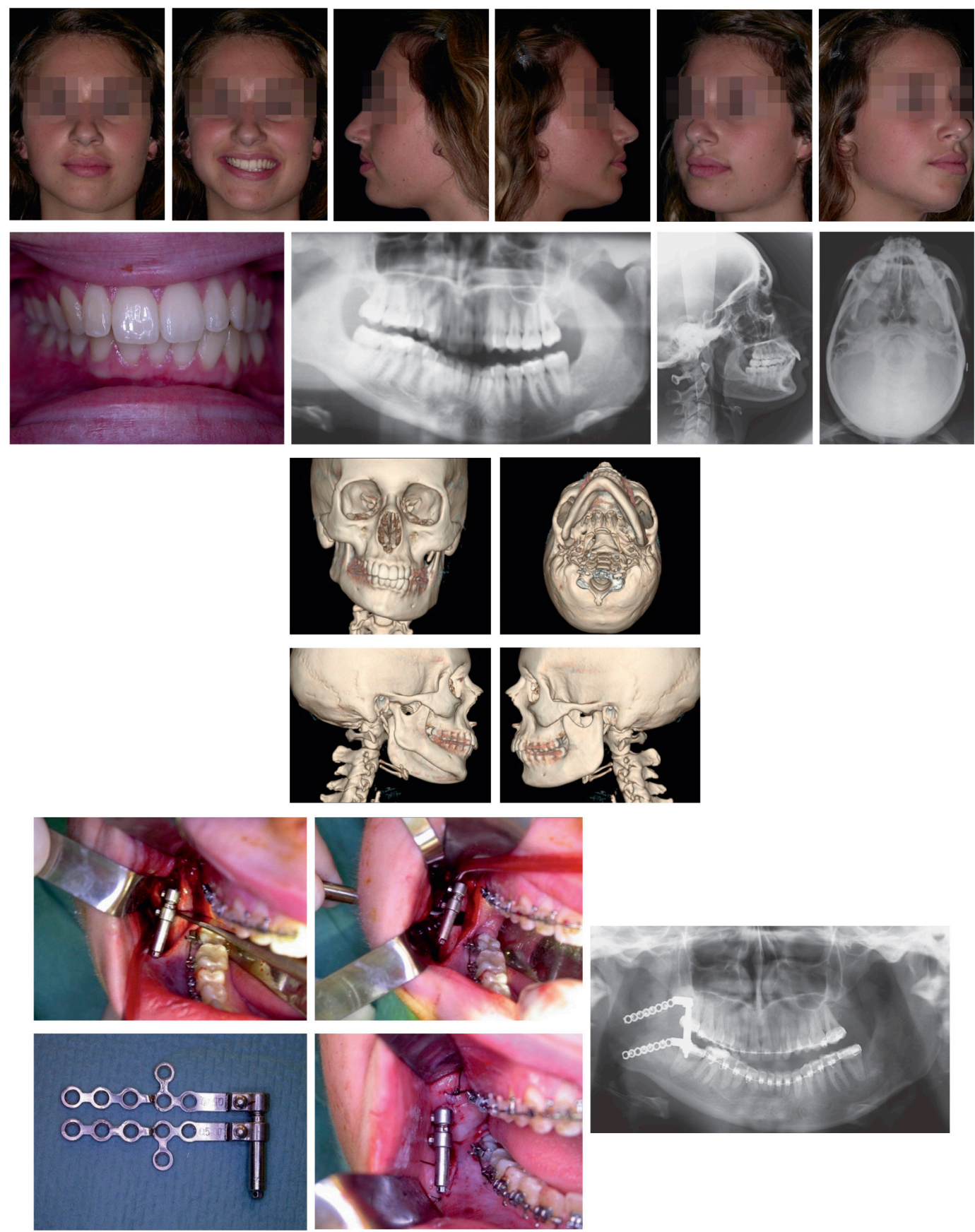

Figure 14

a) Complex case of a unilateral brachyfacial ramus treated with first vertical mandibular distraction. 

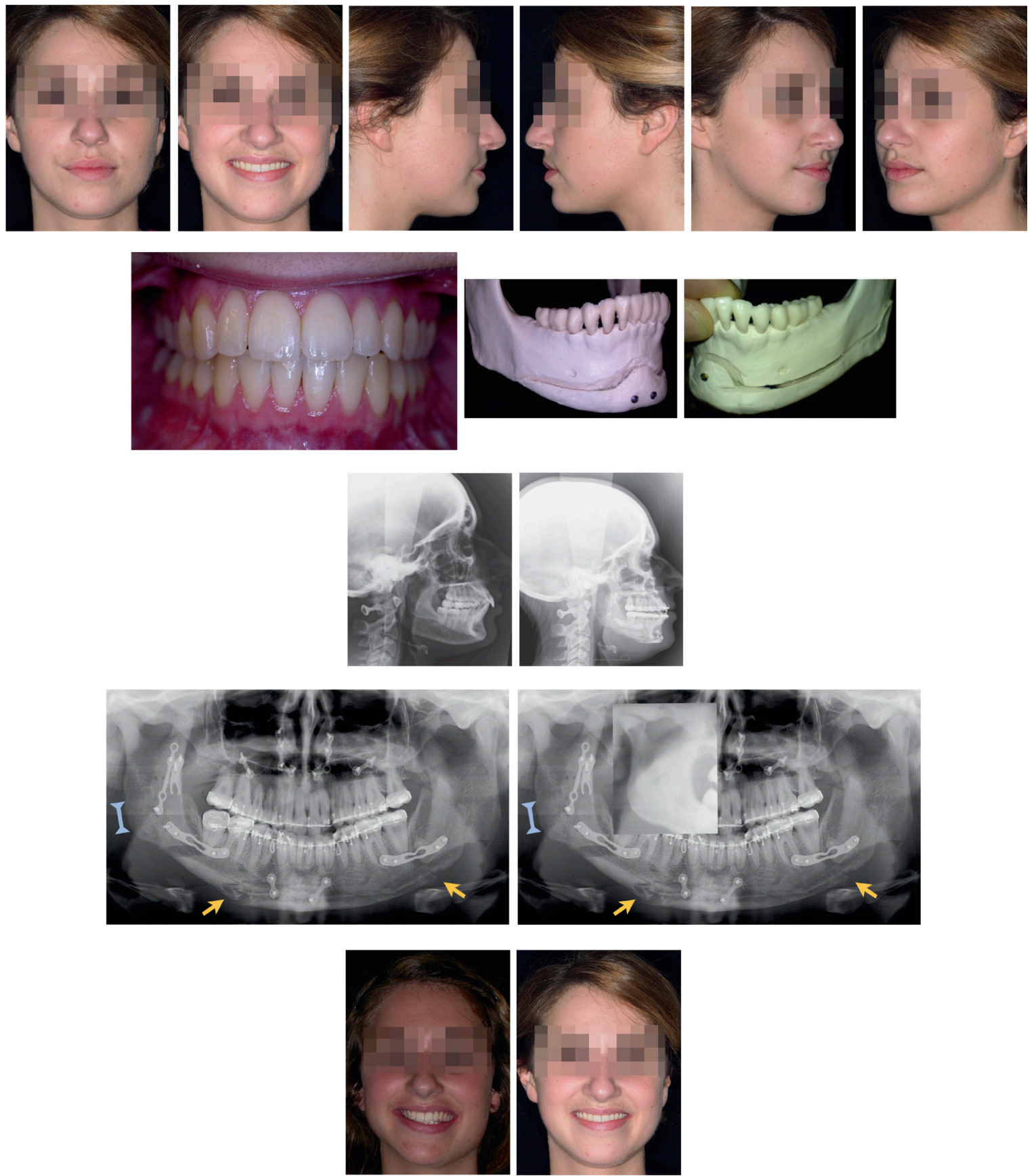

Figure 14

b)... following the orthodontic preparation, is a bimaxillary osteotomy with asymmetric genioplasty of the Chin wings.

\section{Distraction (fig. 14)}

This consists of correcting a developmental disorder by making an osteotomy, followed by the elongation of the proteinaceous bone callus to increase the length of the bone. The first step consists of making a distractor specific to the patient. Once the area of the osteotomy is configured, generally, during ambulatory treatment, a simple intervention, which entails sectioning the bone perpen- 

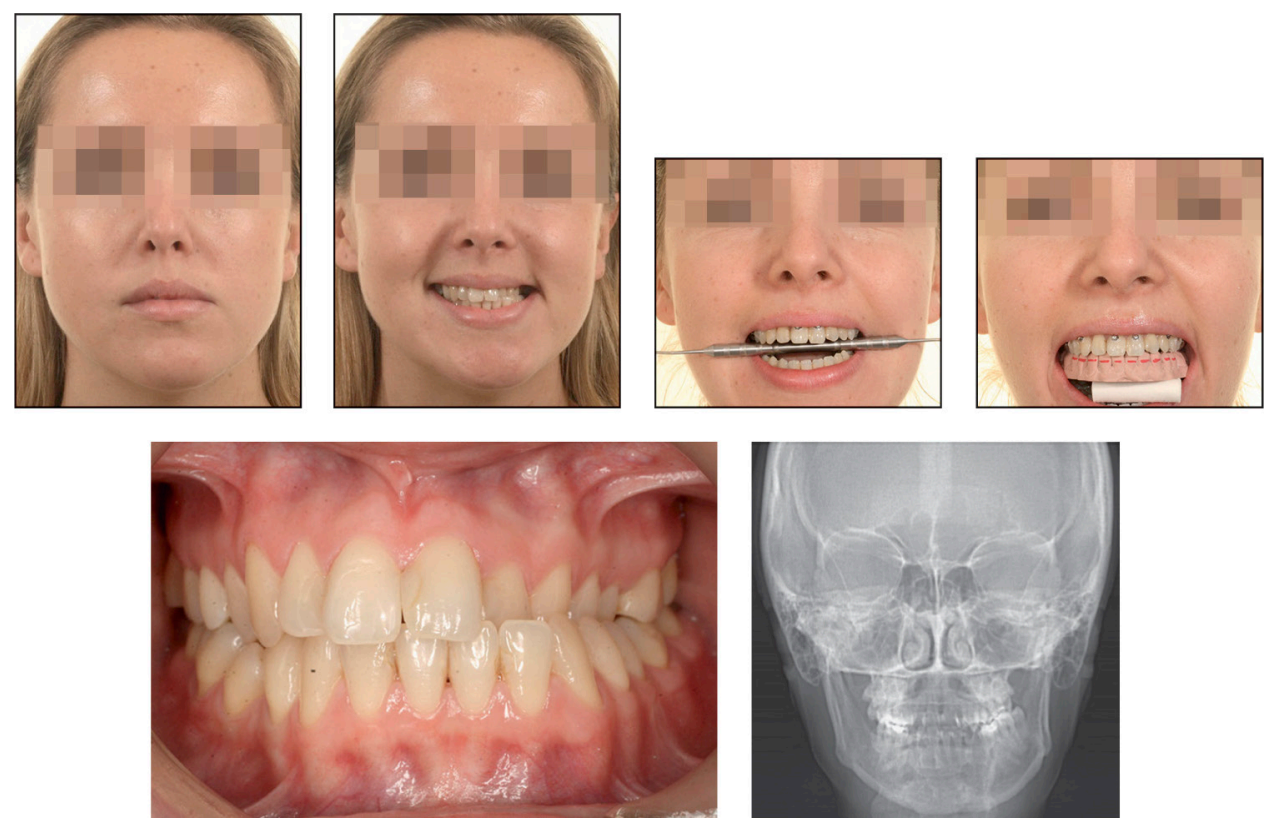

Figure 15

a) Mandibular lateral deviation with a slightly oblique occlusal plane and vertical interincisal midline treated by sagittal osteotomy of sagittal de-rotation and a moderate transverse maxillary deficiency treated by maxillary corticotomies with a graft to improve the orthodontic treatment result.

dicular to the chosen vector of distraction, is done. Periosteal stripping must be minimized to not damage the vascular system in the affected area. Over the course of 5 to 7 days, the proteinaceous callus forms. Then, distraction is performed at a rate of $0.5 \mathrm{~mm}$ to $1 \mathrm{~mm}$ per day (usually in two procedures). It is painless, but it can result in moderate edema. The consolidation phase usually takes 4 to 8 weeks, but this depends on the quality of the outcome. The removal of the distractor usually requires general anesthesia. The limitations of this technique are numerous: the distracted bone is often limited in size and the vector of distraction must be perfectly aligned and eventually modified, which requires the use of multidirectional distractors. The intrabuccal load can cause injuries. Finally, the cost of bone-supported distractors can make the procedure too expensive.

\section{Vertical Osteotomy ${ }^{8,12}$}

The main indication is posterior vertical deficiency with a unilateral or bilateral brachyfacial ramus. It consists of creating a posterior and vertical osteotomy of the mounting branch behind the spine to lengthen the mounting branch and make the mandible symmetrical. It can be performed externally or intrabuccally, but it is a more complex procedure.

\section{Sagittal osteotomy}

"Classic" Obwegeser or Epker sagittal osteotomy facilitates mandibular arch movement in the three planes. The size of the external valves is intentionally asymmetrical during derotations (generally shorter on the opposite side of the rotation) ${ }^{5}$ (fig. 15). 

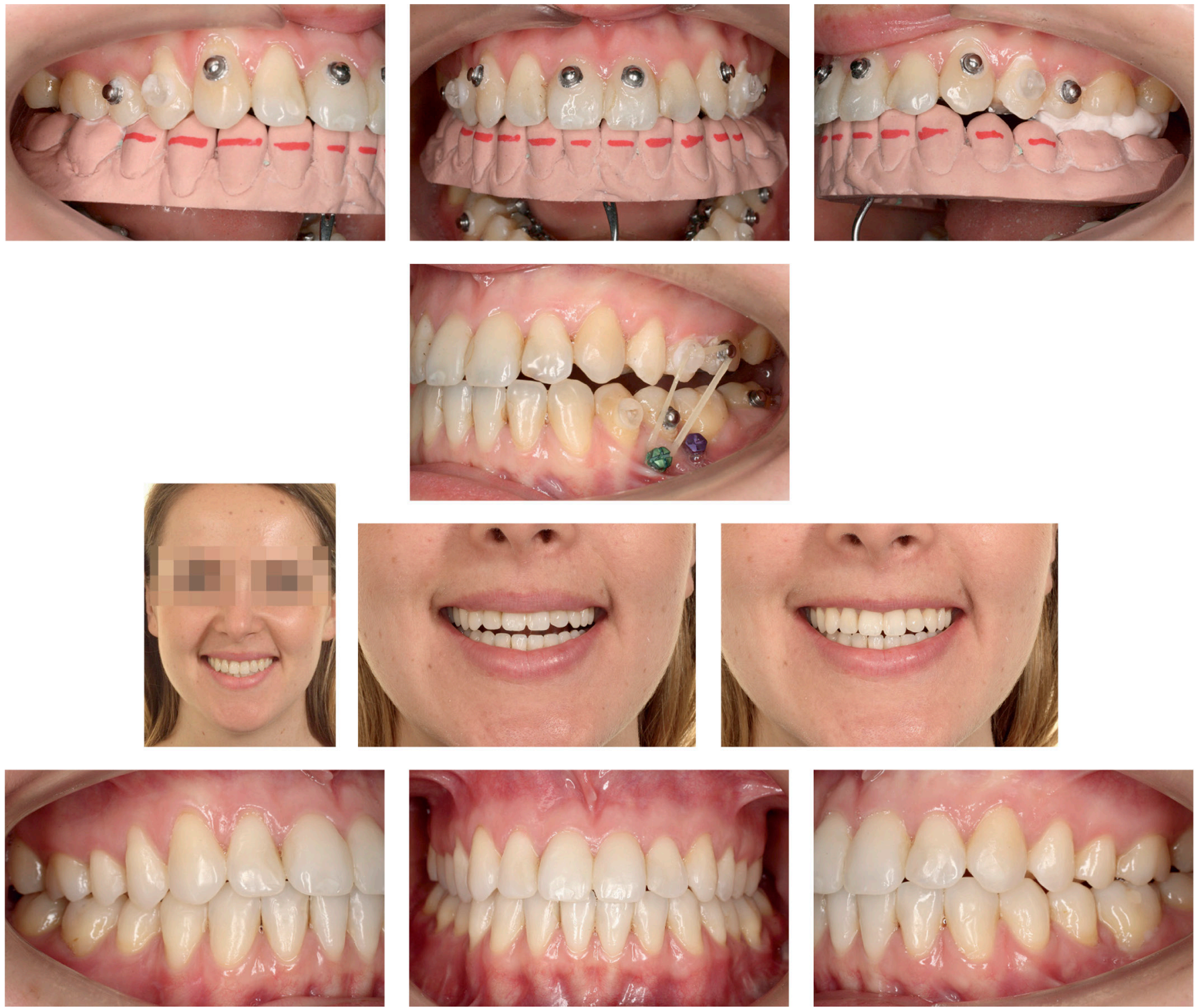

Figure 15

b) Interarch asymmetry of the maxillary arch has been corrected by postoperative orthodontic egression.

\section{Short oblique osteotomy of the de Perthes/Schloessmann mounting branch} (fig. 16, 17)

Recently updated, it allows for better corrections of some mandibular asymmetries by shifting the gonion angles. It is performed intrabuccally, and osteosynthesis requires a special tool bent at $90^{\circ}$. To a certain extent, it permits the lengthening of the mounting branch to correct vertical asymmetries. This lengthening must not be too significant (probably less than $10 \mathrm{~mm}$ ) to keep the fragments in their correct consolidation. 


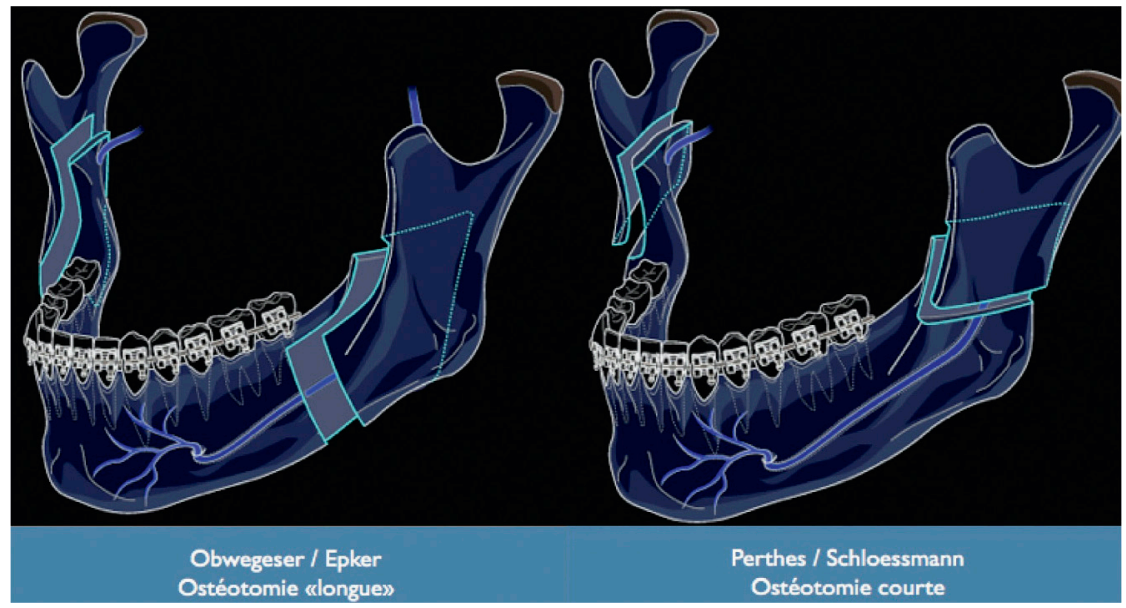

Figure 16

Comparison between sagittal osteotomy and short oblique osteotomy of the mounting branch.
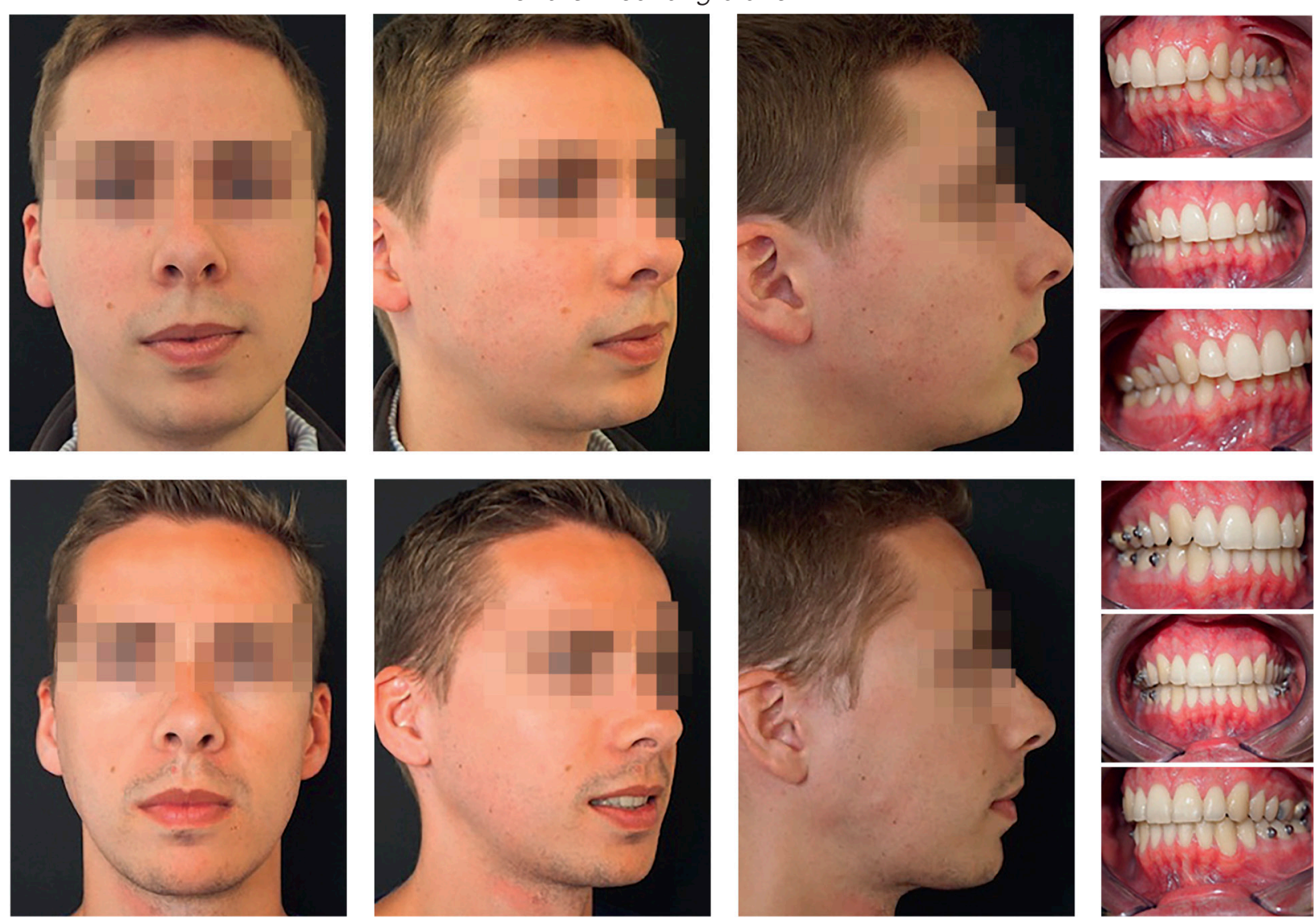

a

Figure 17

Correcting mandibular asymmetry caused by right condylar hyperplasia (Surgeon: Cédric d'Hauthuille, orthodontist: Bernard Nourry, Nantes). a) Before intervention (above) and 1 year after intervention (below). In the same operation: condylectomy via the right preauricular, right ascending Le Fort 1 osteotomy and an advanced short oblique mandibular osteotomy with left angle lowered and right angle raised. 


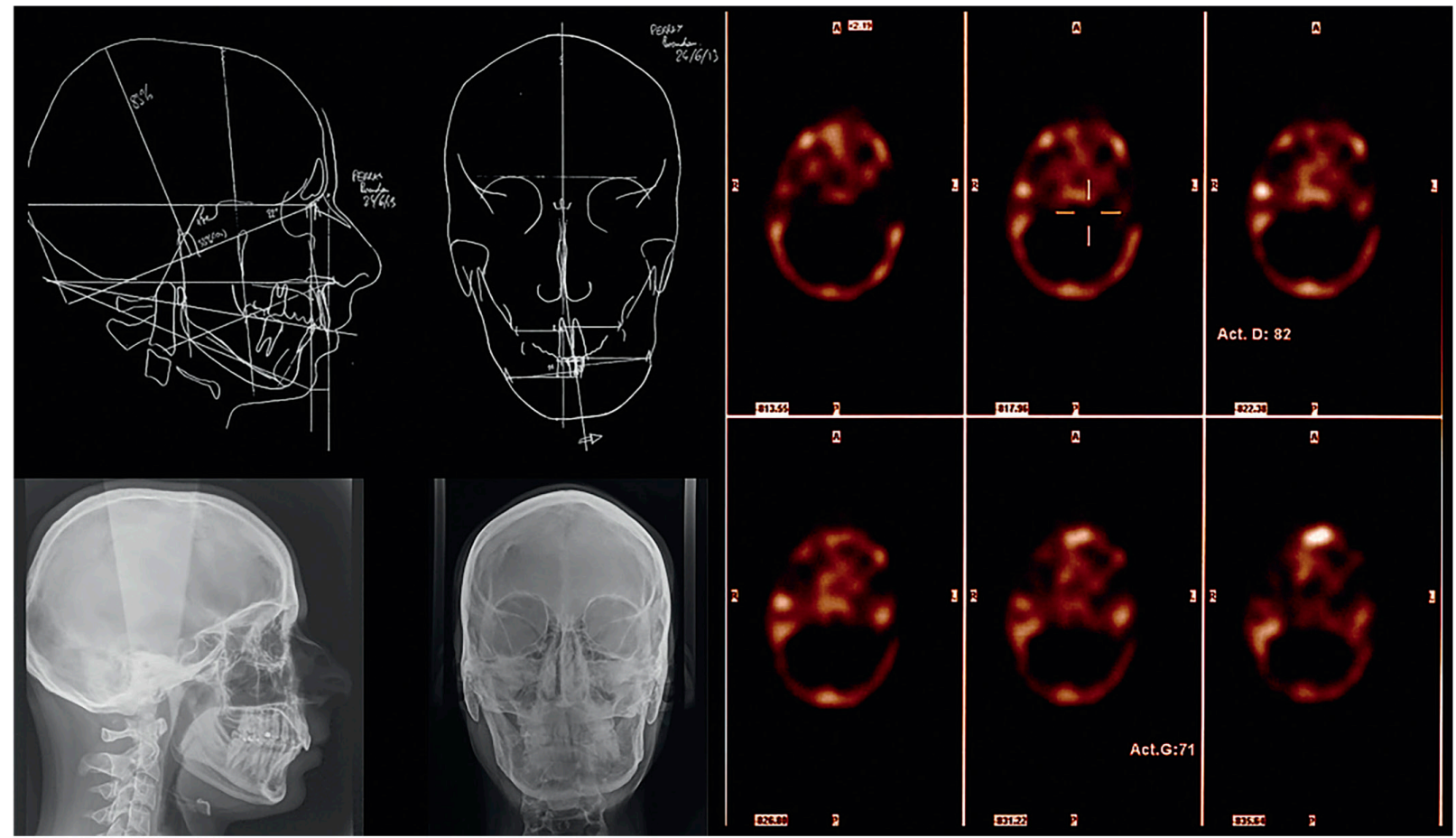

b
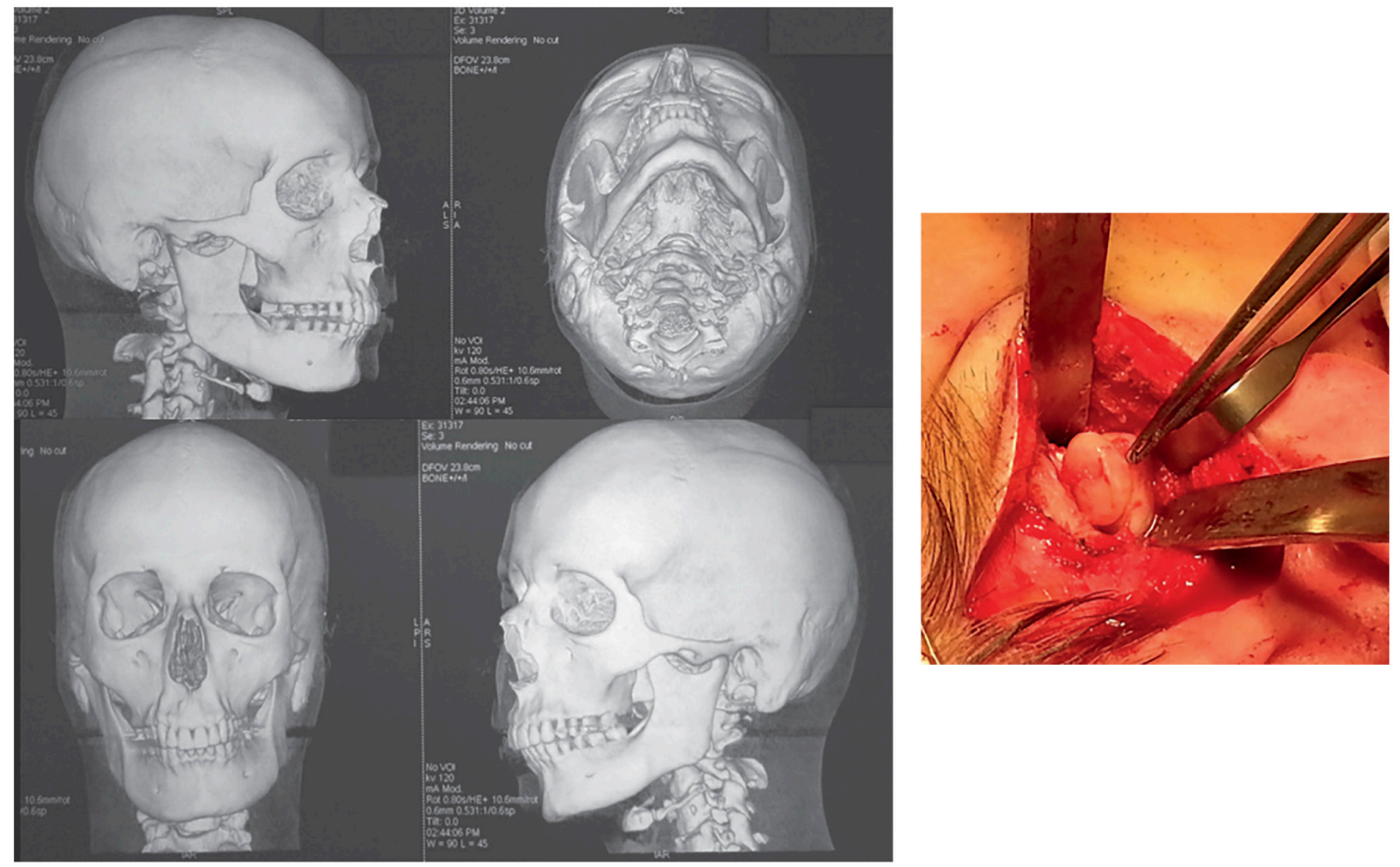

Figure 17

b) Cephalometric analyses using Delaire's protocols, teleradiography, and bone scanning. The bone scan shows right condylar hyperfixation. c) 3D tomodensitometric reconstructions on the left. Operative view of the raising of the condylar bump via the right preauricle. 

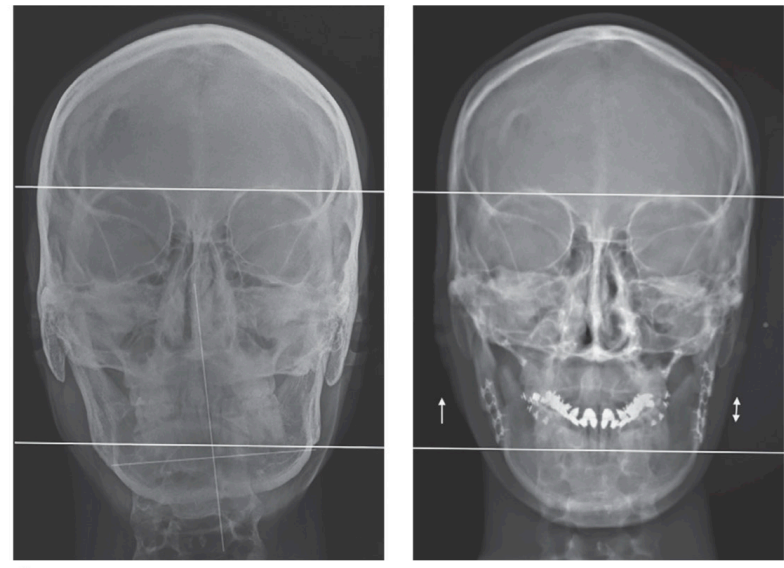

d

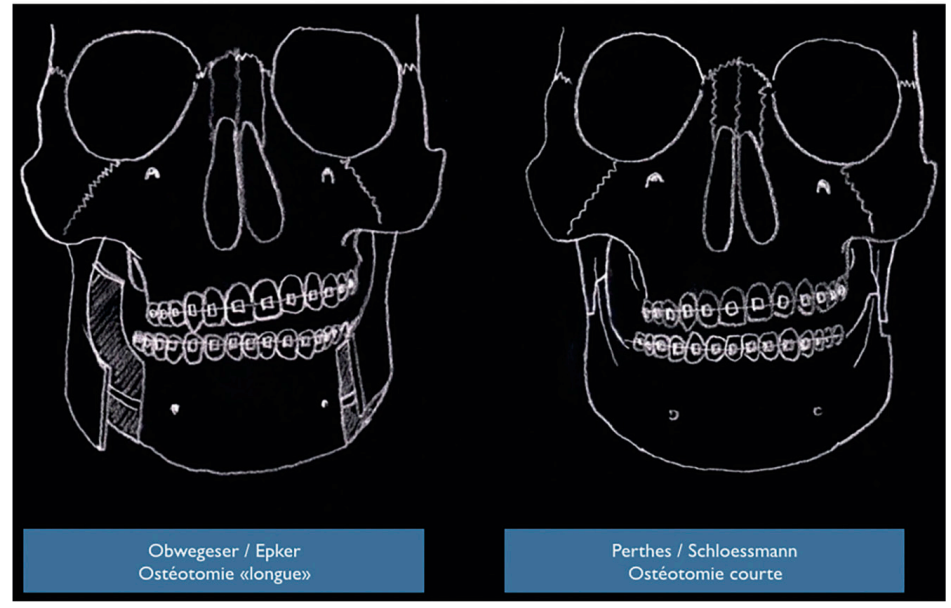

Figure 17

d) Preoperative facial teleradiography on the left and postoperative facial teleradiography on the right. This surgical technique lowers the left side and raises the right side. Comparison of asymmetrical correction by long mandibular osteotomy. Obwegeser or Epker: left and the short mandibular osteotomy technique.

\section{Figure 17}

e) Comparison of the asymmetrical correction via the Perthes/ Schloessmann technique. The placement of the osteotomy line allows you to reduce the difficulty of valve positioning at the same time.

\section{Chin wing genioplasty}

Albino Triaca ${ }^{31,32}$ has revolutionized the surgical treatment of the basilar edge by completely separating it in relation to the placement of the serrated portion. This makes it possible to treat the left and right sides independently, which is vital when dealing with lower-tier asymmetries. This technique lowers the mandibular angle to correct the height of the horizontal branch and thereby correct excessive alveolar height compensations. It is most often associated with 

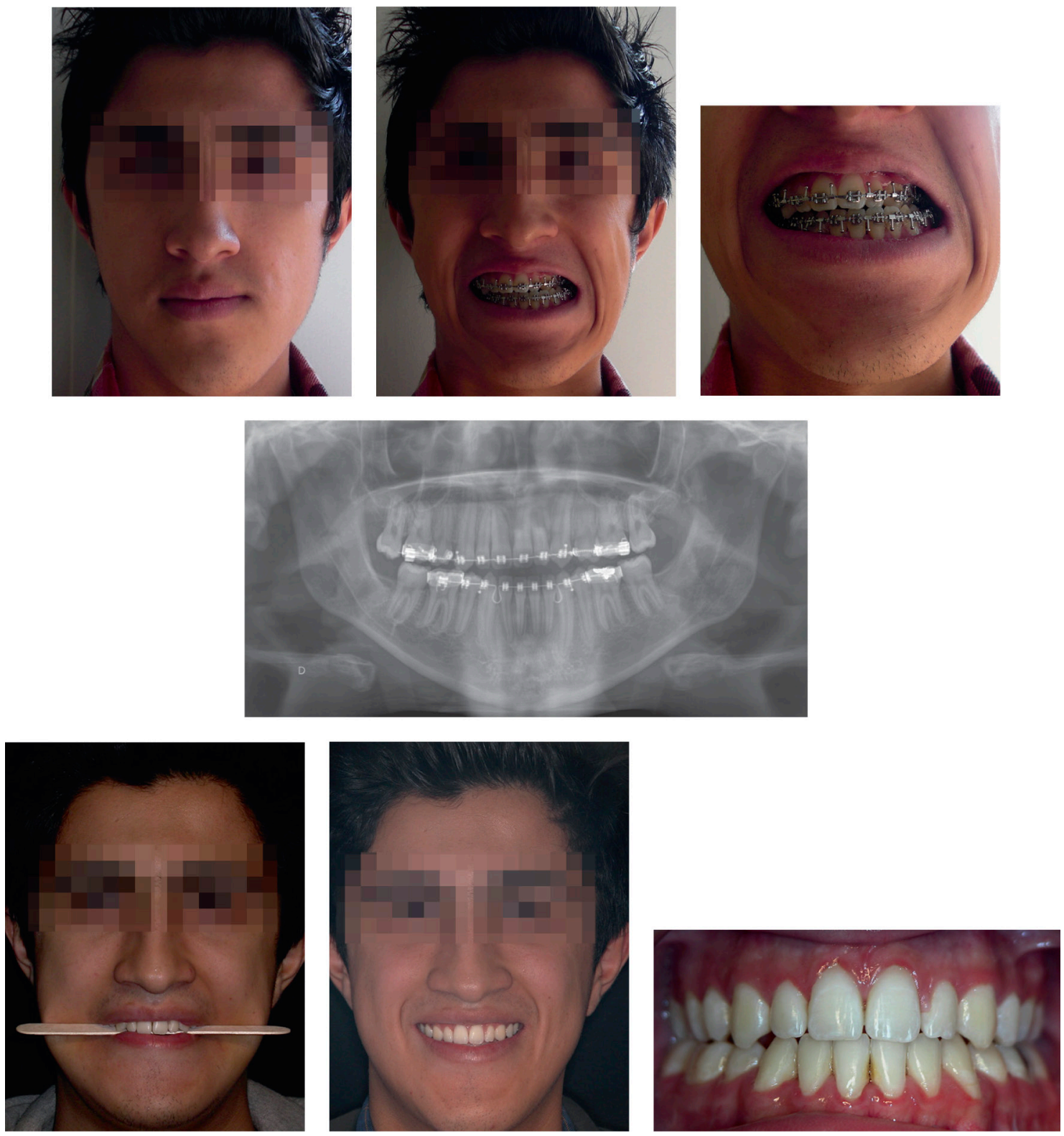

Figure 18

Mandibular lateral deflection with occlusal plane, and shift of maxillary and mandibular/basal bone, treated by bimaxillary osteotomy following orthodontic preparation.

maxillary or mandibular osteotomies (fig. 14).

\section{Bi-maxillary osteotomies}

As seen previously, when the maxillary plane is very oblique or the inter- incisal midline cannot be orthodontically corrected, making a bi-maxillary osteotomy becomes necessary (fig. 18). 


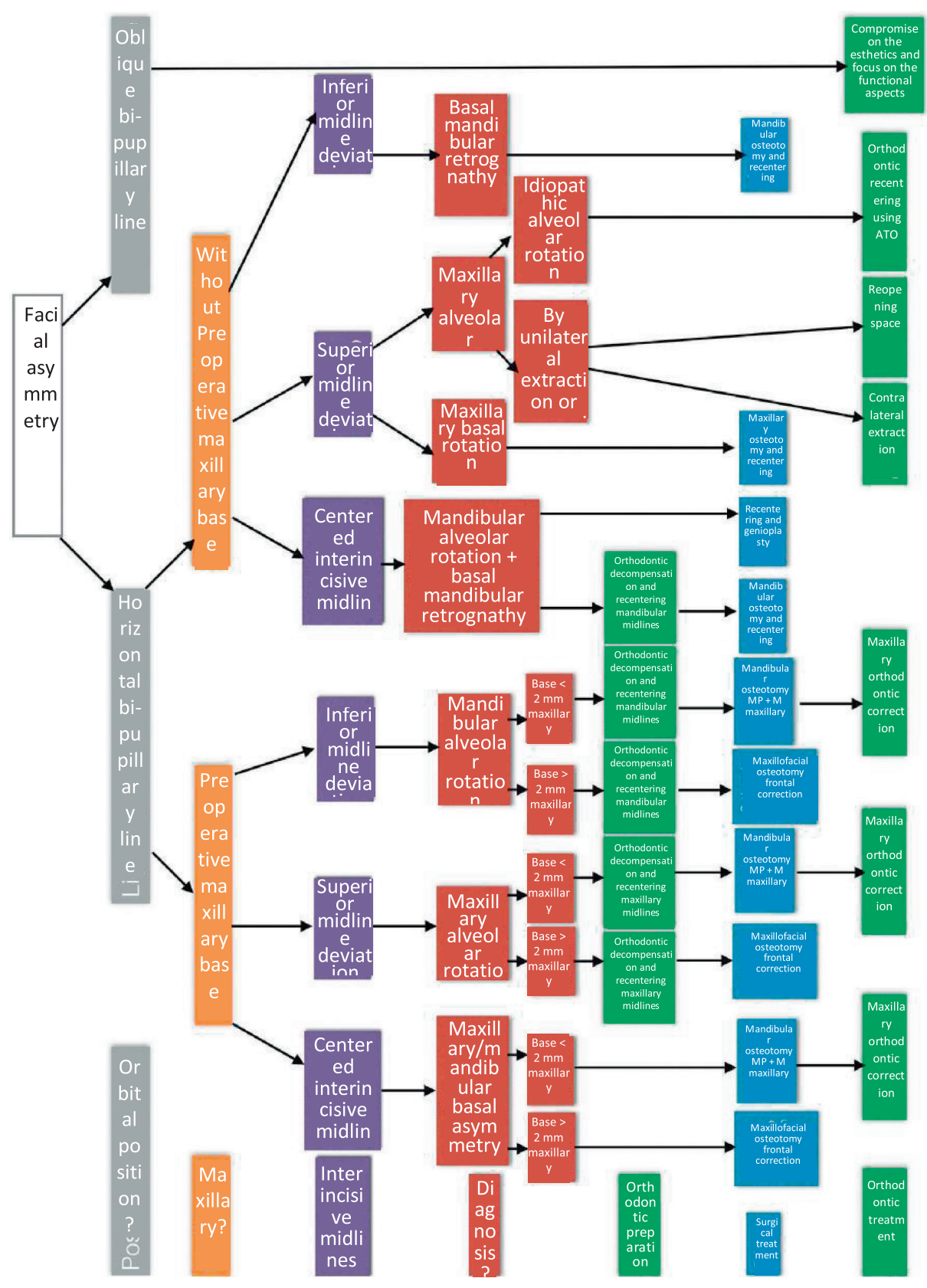

Figure 19

Proposal of an orthodontic and surgical decision tree for facial asymmetries. OP: occlusion plane, OP Max: maxillary plane, Op Mand: mandibular plane, PM +M: premolo-molar. TOA: trans-osseous anchorages. 


\section{CONCLUSION}

Facial asymmetries require a close collaboration and numerous exchanges between the orthodontist and the surgeon. The initial diagnosis is essential and must be refined by combining the two different points of view of the specialists. A common consultation is ideal as it makes it easier to explain the details of the treatment plan to the patient. Treatment for these patients can range from simple to very complicated. Sometimes, it may in-

\section{ACKNOWLEDGEMENTS}

Special thanks to Drs. Marine Abadie (ODF, Paris), Éric Allouch (ODF, Levallois), Isabelle Brandy (ODF, Bondy), Tho Dang (ODF, Genève), Mohamed El Okeily (Chir Maxillo, Bordeaux), Jean-Paul Forestier (ODF, MCU Paris), Karine Gabison (ODF, Paris), Matthieu Granvaud (ODF, Paris), Cédric d'Hauthuille (Chir Maxillo, Nantes), Guillaume Joseph (ODF, Pertuis), Adrien Marinetti (ODF, Paris), volve standard orthodontic alignment followed by mandibular de-rotation. In other cases, complex, orthodontic decompensation with bone anchorages, wedges, and sectional mechanics is required. This is followed by multi-phase surgical procedures. The stages that these patients must endure to prevent the possibilities of relapse and orthodontic surgical overcorrection are constantly changing. Surgical intervention is often useful.
Bernard Nourry (ODF, Nantes), Tania Stakovski (ODF, Paris), Bertrand Szustakiewicz (ODF, Limoges), Benoit Thébault (ODF, Redon), Steve Toupenay (Spéc. Méd. Buc. Dentaire, Paris), Albino Triaca (Chir. Maxillo, Zurich), Hanh Vuong (ODF, Paris).

Conflict of interest: The authors have declared that they do not have any conflict of interest.

\section{BIBLIOGRAPHY}

1. Bazert $\mathrm{C}$, et al., [Etiopathogenic and clinical aspects of asymmetry]. Orthod $\mathrm{Fr}$ 2002;73(2):125-178.

2. Berssenbrugge $P$, et al. $2 D$ and $3 D$ analysis methods of facial asymmetry in comparison. J Craniomaxillofac Surg 2014;42(6):e327-334.

3. Bhateja NK, Fida M, Shaikh A. Frequency of dentofacial asymmetries: a cross-sectional study on orthodontic patients. J Ayub Med Coll Abbottabad 2014;26(2):129133.

4. Billet M, Cadre B. Hypercondylie. Revue d'Orthopédie Dento-Faciale 2013;47(2):173.

5. Charrier J-B. Chirurgie orthognathique de l'adulte et esthétique faciale. Revue d'Orthopédie Dento-Faciale 2012;46(2):23. 
6. Chauvel-Lebret D, Leroux A, Sorel O [Relations between orthognathic surgery and temporoman-dibular disorders: a systematic review]. Orthod Fr 2013;84(2):169-183.

7. Cheong YW, Lo LJ. Facial asymmetry: etiology, evaluation, and management. Chang Gung Med J 2011;34(4):341-351.

8. Deffrennes. Ostéotomies maxillomandibulaires : techniques chirurgicales et indications. EMC Elsevier Masson. Vol. Techniques chirurgicales - Chirurgie plastique reconstructrice et esthétique. 2015.

9. Gateno J, Alfi D, Xia JJ, Teichgraeber JF. A Geometric Classification of Jaw Deformities. J Oral Maxillofac Surg 2015;73(12 Suppl):S26-31.

10. Gateno J, Jajoo A, Nicol M, Xia JJ. The primal sagittal plane of the head: a new concept. Int J Oral Maxillofac Surg 2016;45(3):399-405.

11. Guyot L, Seguin P, Benateau H. Techniques en chirurgie maxillo-faciale et plastique de la face. Springer Science \& Business Media 2011:295 p.

12. Hara $S$, Mitsugi M, Hirose $H$, Tatemoto $Y$. Combination of Mandibular Constriction and Intraoral Vertical Ramus Osteotomies for a Transverse Jaw Discrepancy. Plast Reconstr Surg Glob Open 2015;3(9):e521.

13. Jiang $\mathrm{N}$, et al. Total or partial inferior border ostectomy for mandibular contouring: indications and outcomes. J Craniomaxillofac Surg 2012;40(8):e277-284.

14. Junqueira $\mathrm{CH}$, Janson G, Junqueira MH, Mendes LM, Favilla EE, Garib DG. Comparison between full face and hemifacial CBCT cephalograms in clinically symmetrical patients: a pilot study. Dental Press J Orthod 2015;20(2):83-89.

15. Krim M, MK, Lachachi B, Merad S, Berber N. Bilan scin-tigraphique osseux d'une hypercondylie unilatérale. EMC Elsevier Masson, 2012. Médecine Nucléaire 36(5):299302.

16. Longis J. Reconstruction du ramus mandibulaire par greffe chondro-costale, étude rétrospective à propos de 54 cas. 2012.

17. Lopez PE, Guerrero CA, Mujica EV. Mandibular basal osteotomy: new designs and fixation techniques. J Oral Maxillofac Surg 2011;69(3):786-797.

18. Mascarelli PF. Examen clinique de la face en ortho-pédie dento-faciale. EMC Elsevier Masson, 2010.

19. Mercier JM, Perrin JP, Longis J, Arzul L, Corre P. [Facial asymmetries and their skeletal component]. Rev Stomatol Chir Maxillofac Chir Orale 2014;115(4):2192-28.

20. Munoz R, Diaz A, Golaszewski J. Modified basal oste-otomy combined with osteogenic distraction (Hemi-Wing distraction) for correction of facial asymmetry: A new technique. Ann Maxillofac Surg 2014;4(2):186-188.

21. Obwegeser HL. Mandibular growth anomalies : terminology, aetiology, diagnosis and treatment. Springer Berlin, 2001.

22. Sanders DA, Chandhoke TK, Uribe FA, Rigali PH, Nanda R. Quantification of skeletal asymmetries in normal adolescents: cone-beam computed tomography analysis. Prog Orthod 2014;15(1):26.

23. Sándor GK, McGuire TP, Ylikontiola LP, Serlo WS, Pirttiniemi PM. Management of facial asymmetry. Oral Maxillofac Surg Clin North Am 2007;19(3):395-422, vi.

24. SevertTR, Proffit WR. The prevalence of facial asymmetry in the dentofacial deformities population at the University of North Carolina. Int J Adult Orthodon Orthognath Surg 1997;12(3):171-176.

25. Sheats RD, McGorray SP, Musmar Q, WheelerTT, King GJ. Prevalence of orthodontic asymmetries. Semin Orthod 1998;4(3):138-145.

26. Souyris F, Moncarz V, Rey P. Facial asymmetry of developmental etiology. A report of nineteen case. Oral Surg Oral Med Oral Pathol 1983;56(2):113-124. 
27. Thiesen G, Gribel BF, Freitas MP. Facial asymmetry: a current review. Dental Press J Orthod 2015;20(6):110-125.

28. Treil J. Braga J, Ait Ameur A. [3D representation of skull and soft tissues. Usefulness in orthodontic and orthognathic surgery]. J Radiol 2009;90(5 Pt 2):634-641.

29. Treil J, Casteigt J, Borianne P, Faure J. [3D cephalom-etry]. Orthod Fr 2000;71(2): 153-154.

30. Treil J, Casteigt J, Borianne P, Madrid C, Jaeger M, de Bonnecaze P. [The architectural balance of the face: a 3D cephalometric concept]. Rev Stomatol Chir Maxillofac 1999;100(3):111-122.

31. Triaca A, Brusco D, Guijarro-Martinez R. Chin wing osteotomy for the correction of hyper-divergent skeletal class III deformity: technical modification. Br J Oral Maxillofac Surg 2015;53(8):775-777.

32. Triaca A, Minoretti R, Saulacic N. Mandibula wing osteotomy for correction of the mandibular plane: A case report. Br J Oral Maxillofac Surg 2010;48(3):182-184.

33. Wenghoefer $M$, Peters $A$, Reich RH. Modified tria-ca-style wing osteotomy to correct facial asymmetry in a patient with horizontal growth-type condylar hyper-plasia. J Craniofac Surg 2013;24(5):1769-1771.

34. Xia JJ, et al. Algorithm for planning a double-jaw orthognathic surgery using a computer-aided surgical simulation (CASS) protocol. Part 1: planning sequence. Int J Oral Maxillofac Surg 2015;44(12):1431-1440.

35. Xia JJ, et al. Algorithm for planning a double-jaw orthognathic surgery using a computer-aided surgical simulation (CASS) protocol. Part 2: three-dimensional cephalometry. Int J Oral Maxillofac Surg 2015;44(12):1441-1450. 